\title{
Risk markers for fatal and non-fatal prescription drug overdose: a meta-analysis

Joanne E. Brady ${ }^{1 *}$, Rebecca Giglio ${ }^{2}$, Katherine M. Keyes ${ }^{1,2}$, Charles DiMaggio ${ }^{3}$ and Guohua Li $i^{1,2,4}$

\begin{abstract}
Background: Drug overdose is a public health crisis in the United States, due in part to the unintended consequences of increases in prescribing of opioid analgesics. Many clinicians evaluate risk markers for opioid-related harms when prescribing opioids for chronic pain; however, more data on predictive risk markers are needed. Risk markers are attributes (modifiable and non-modifiable) that are associated with increased probability of an outcome. This review aims to identify risk markers associated with fatal and non-fatal prescription drug overdose by synthesizing findings in the existing peer-reviewed and grey literature. Eligible cohort, case-control, cross-sectional, and case-cohort studies were reviewed and data were extracted for qualitative and quantitative synthesis.

Findings: Summary odds ratios (SOR) were estimated from 29 studies for six risk markers: sex, age, race, psychiatric disorders, substance use disorder (SUD), and urban/rural residence. Heterogeneity was assessed and effect estimates were stratified by study characteristics. Of the six risk markers identified, SUD had the strongest association with drug overdose death $(\mathrm{SOR}=5.24,95 \%$ confidence interval $(\mathrm{Cl})=3.53-7.76)$, followed by psychiatric disorders (SOR $=3.94$, $95 \% \mathrm{Cl}=3.09-5.01)$, white race $(\mathrm{SOR}=2.28,95 \% \mathrm{Cl}=1.93-2.70)$, the 35-44 year age group relative to the 25-34 year reference group ( $\mathrm{SOR}=1.52,95 \% \mathrm{Cl}=1.31-1.76)$, and male sex $(\mathrm{SOR}=1.33,95 \% \mathrm{Cl}=1.17-1.51)$.

Conclusions: This review highlights fatal and non-fatal prescription drug risk markers most frequently assessed in peer-reviewed and grey literature. There is a need to better understand modifiable risk markers and underlying reasons for drug misuse in order to inform interventions that may prevent future drug overdoses.
\end{abstract}

Keywords: Accidents, Analgesics, Opioid/toxicity, Drug overdose, Mortality, Prescription drugs/toxicity, Prevalence, Public health, Risk factors, Substance-related disorder

\section{Review}

Unintentional drug poisoning (overdose) is defined by the Centers for Disease Control and Prevention (CDC) as accidental harm caused by the ingestion, inhalation, injection or absorption of a substance that is not intended to cause harm (Centers for Disease Control and Prevention 2015). Overdose deaths have been increasing for the past 20 years (Warner et al. 2011; Centers for Disease Control and Prevention 2012; Rudd 2016); prescription drug overdose (PDO) deaths have played a considerable role in the drug overdose epidemic (Centers for Disease Control and Prevention 2012; Warner et al. 2009; Okie 2010). Increases in PDO deaths have coincided with an increase in

\footnotetext{
* Correspondence: jb3042@cumc.columbia.edu

'Department of Epidemiology, Columbia University Mailman School of Public Health, New York, NY, USA

Full list of author information is available at the end of the article
}

nonmedical use of prescription drugs and prescription drug-related morbidity (Centers for Disease Control and Prevention 2012; Okie 2010; Centers for Disease Control and Prevention 2011; Dhalla et al. 2009; Coben et al. 2010; Cai et al. 2010). The rise in overdose is largely attributable to greater therapeutic and nonmedical prescription drug use and abuse, specifically use and abuse of opioid analgesics (Centers for Disease Control and Prevention 2015; Centers for Disease Control Prevention 2005; Centers for Disease Control Prevention 2011; Mueller et al. 2006; Wunsch et al. 2009; Centers for Disease Control Prevention 2012). These increases have led to numerous regulatory changes in many states, as well as a new prescribing guideline to help providers evaluate risk markers for opioid-related harms when prescribing opioids for chronic pain (Dowell et al. 2016). 
Risk markers are attributes that are associated with increased probability of an outcome, and may or may not be modifiable or causal factors (Burt 2001). PDO risk markers may be important for informing public health interventions (Keyes et al. 2014; Diez Roux 2004). However, studies of PDO have not consistently identified the same risk markers or the same effects (Bohnert et al. 2012; Bohnert et al. 2011; Dunn et al. 2010; Havens et al. 2011a; Cochella and Bateman 2011; McKenzie and McFarland 2007; Silva et al. 2013) and there has not been a systematic evaluation of risk markers associated with PDO. Extant reviews and studies of PDO and drugrelated mortality have been narrative or have focused on trends over time, but have not systematically evaluated the evidence in support of various risk markers (Warner et al. 2011; Warner et al. 2009; Centers for Disease Control Prevention 2005; Buckley and McManus 2004; Crombie and McLoone 1998; Gilchrist et al. 2012; Bateman et al. 2003; Degenhardt et al. 2001; Fernandez et al. 2006; Fischer et al. 2006; Green et al. 2011; Hall et al. 1999; Lynskey and Hall 1998; Paulozzi and Xi 2008; Paulozzi et al. 2006; Rosca et al. 2012; Romelsjo et al. 2010; Roxburgh et al. 2011; Shah et al. 2005; Shah et al. 2012; Williamson et al. 1997; Wong et al. 2010; Harlow 1991; Lloyd and McElwee 2011; Paulozzi and Stier 2010; Paulozzi et al. 2012).

This review aims to provide a comprehensive and quantitative evaluation of the existing literature concerning the most frequently examined risk markers associated with PDO. Six commonly examined risk markers were identified for further investigation: sex, age, race, comorbid psychiatric disorder, comorbid substance use disorder (SUD) and urban/rural area of residence. Understanding risk markers may help identify modifiable factors which may be intervened upon, and aid in the identification of individuals at greatest risk for PDO. This review examines characteristics of previous research studies, in order to understand differences in their findings, identify salient gaps in the PDO literature and ultimately to help inform policy and guide decision-making regarding preventive interventions to curb PDO.

\section{Methods}

Reporting in this meta-analysis followed standard methodology, adhering to the procedural and reporting recommendations for conducting meta-analyses outlined in the PRISMA statement and MOOSE guidelines (Moher et al. 2009; Stroup et al. 2000).

\section{Eligibility}

This review contains two components: 1) a systematic descriptive review, and 2) a systematic quantitative meta-analysis. To be included, a study must have been published in the English language from January 1, 1990 to December 1, 2016. Included studies used a standard epidemiologic study design (e.g., cohort, case-control, cross-sectional, case-cohort study or survey) from which effect measures could be extracted. Publications reporting on case-series (e.g., medical examiner data with no non-events and not including rates, comparative case-series, letters, editorials commentaries, opinion pieces), case reports, reviews, time-series or trend studies were excluded. If two studies examined the same outcome in the same individuals during the same time period, but examined a different control series, only the study published first was included (Lanier et al. 2012; Johnson et al. 2012; Cheng et al. 2013).

In this review, prescription drugs are defined as any drug requiring a prescription from a licensed healthcare provider, including controlled and non-controlled substances. Studies that focus on illegal drugs, excluding prescription drugs, or that give no indication of prescription drug use were excluded. As this review examines factors associated with accidental (fatal and non-fatal) PDO, studies that exclusively examine suicide or selfpoisoning were excluded. Further, studies that did not consider risk markers for overdose were excluded, as were studies focusing on: infants or children under 12; overdose after drug treatment; recurrent overdose; or the effects of an intervention or policy.

\section{Databases, search strategy and criteria}

Relevant literature was identified through electronic searches of databases: Medline OVID (1946-present), Cochrane Library (1960-present), Cumulative Index to Nursing and Allied Health Literature (1981-present), PsycInfo (1967-present), Scopus (1996-present) and ISI Web of Knowledge (1968-present). Relevant literature examined included peer-reviewed, published papers, abstracts and papers presented at scientific conferences, as well as "grey literature". Grey literature was identified through manual review of relevant reference lists. Electronic databases were searched using Medical Subject Heading keywords for indexed databases (Medline and PsycInfo) and keywords for indexed and non-indexed databases. A medical librarian was consulted to review the databases searched, search terms and search strategy (Appendix 1).

\section{Study selection}

After electronic search, duplicate citations were removed. Titles of references were reviewed for relevancy to ensure the article examined PDO. The abstracts of potentially relevant titles were reviewed to further assess a study's eligibility for inclusion. If the study abstract was considered eligible, the full text of the study was retrieved and evaluated to determine if the study was eligible for inclusion. Two reviewers independently reviewed the full text of 
studies identified for inclusion. In cases of disagreement, the study was discussed until consensus was reached.

\section{Data extraction}

Information about the characteristics of each study was extracted, and data were extracted to identify the most commonly studied risk markers, and to calculate the unadjusted odds ratio of PDO. This was done in two steps: 1) information on risk markers for PDO was collected from each study, and 2) a list was generated to compare which risk markers for PDO were most frequently examined. Risk marker information was categorized into common domains, and risk markers were consolidated where possible (not shown). If a paper was deemed eligible for inclusion, but data on the number of individuals with the outcome or the risk marker of interest were not extractable, the corresponding author of the paper was contacted for additional information. Articles meeting these criteria were selected for qualitative review and characteristics of these studies were reviewed. Risk markers (sex, age, race, comorbid psychiatric disorder, comorbid SUD and urban/rural of the area of residence) were selected for the quantitative analysis when five or more studies examined the same risk marker.

\section{Quality assessment}

After full-text review, the quality of studies eligible for inclusion was evaluated. Quality of relevant studies identified through automated search and hand search of references was evaluated using the Newcastle-Ottawa Quality Assessment Scale (Wells et al. 2011). Quality assessments of cross-sectional studies were evaluated using the modified Newcastle-Ottawa Quality Assessment Scale (Herzog et al. 2013).

\section{Data synthesis and analysis}

The unadjusted odds ratio measuring the association of each risk marker with PDO was estimated for each study. Forest plots were created to show the distribution of effect estimates across studies for each risk marker studied. Heterogeneity was assessed using two statistics - Cochran's Q test statistic and its corresponding $p$-value, and $\mathrm{I}^{2}$ statistics. The $\mathrm{Q}$ statistic tests the null hypothesis that each study evaluates the same effect, whereas the $\mathrm{I}^{2}$ indicates the proportion of total variation across studies that is due to unexplained heterogeneity (Higgins and Thompson 2002). For the Q statistic, a $p$-value of $\leq 0.05$ was considered statistically significant and the effect estimates from the studies were considered heterogeneous. An $\mathrm{I}^{2}$ above 0.5 is considered heterogeneous (Higgins and Thompson 2002). If a heterogeneous result is found, summary effect estimates from a random effects models should be considered
(Riley et al. 2011). For comparison purposes and as a test of sensitivity of the results to model choice, the results of both fixed and random effects model are presented in all forest plots.

When the number of studies permitted, sources of heterogeneity were investigated by stratification analysis according to study design, study quality assessment score, fatal vs combined fatal and nonfatal overdose outcomes, and whether the study outcome was any overdose, medication overdose, PDO or prescription opioid overdose. Heterogeneity was evaluated for each stratified analysis. "One study removed" sensitivity analyses were conducted to assess the robustness of the summary odds ratio. Publication bias was assessed with funnel plots (not shown) and Rosenthal's fail-safe N (Persaud 1996). Analyses were conducted in Microsoft Excel 2010 (Microsoft Corporation, Redmond, Washington), Comprehensive Meta-Analysis version 2 (Biostat Inc., Englewood, New Jersey) and SAS version 9.4 (Statistical Analysis Software, Cary, North Carolina).

\section{Results}

Electronic database searching generated 10,068 references of potential relevance. An additional 70 references were identified through manual review of the references of the studies that underwent quality assessment. From the potentially relevant references, 1771 duplicate references were removed, leaving a total of 8367 records to be screened by title, study design and abstract content. After title review and exclusion of commentaries, and case reports, 186 references remained. The full-texts of these references were acquired. After further review, 29 studies were deemed eligible for the qualitative and quantitative synthesis (Fig. 1). These 29 studies were evaluated according to their study design using the Newcastle-Ottawa Quality Assessment Scale (Tables 1, 2, 3). In this version of the assessment scale, the best possible assessment scale score varies by study design, where the highest possible score for case-control and cross-sectional studies is a 10 and the highest possible score for cohort studies is a 9. A higher score denotes a better quality study. Overall, the case-control and cohort studies were of high quality, with mean assessment scale scores of 9.0/10 and 8.1/9 for case-control and cohort studies respectively. The cross-sectional studies had a mean scale score of 5.4/10.

\section{Characteristics of included studies}

Of the 29 studies included, only three investigated study populations outside the United States (Tables 4 and 5) (Gomes et al. 2011; Hulse et al. 2001; Caudarella et al. 2016) and one exclusively examined adolescents (Hulse et al. 2001). Of the remaining 26 studies, nine considered 


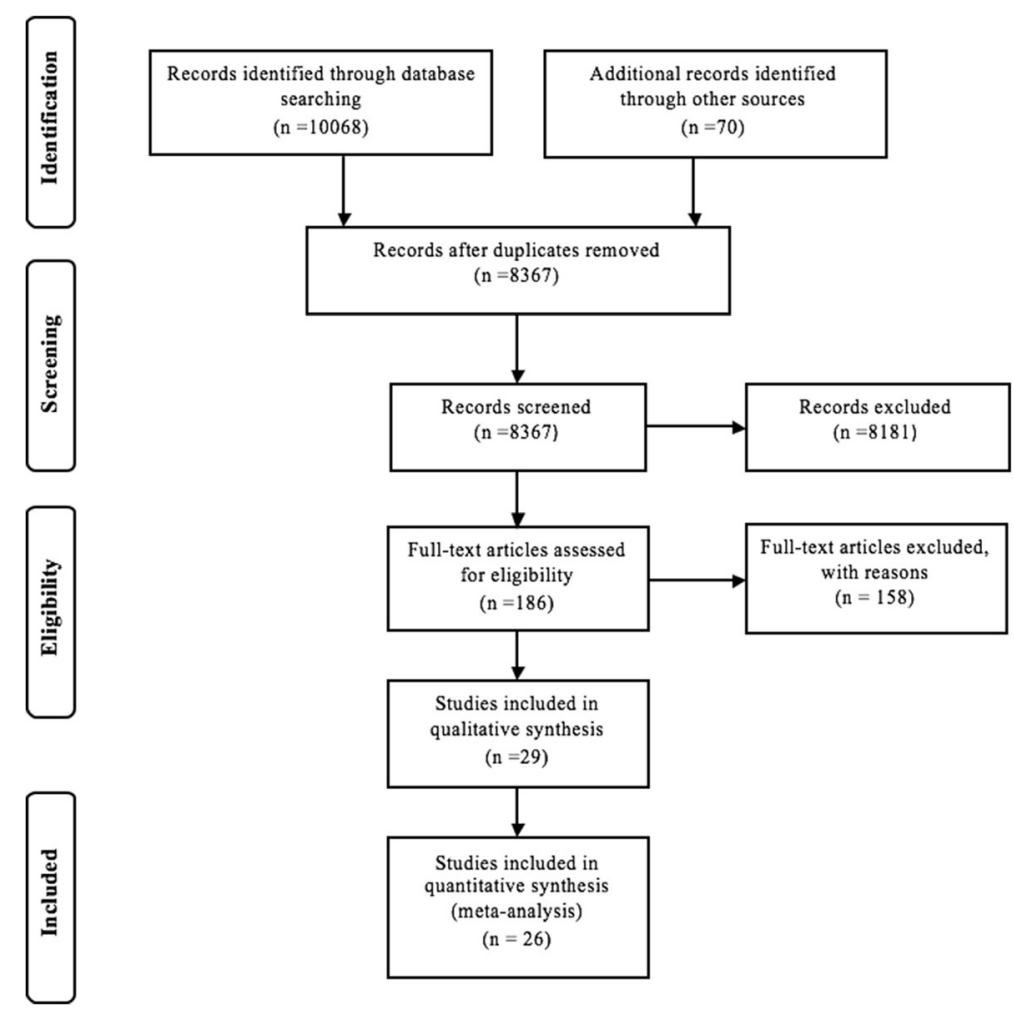

Fig. 1 Flow diagram of the identification, review and selection of included prescription drug overdose meta-analysis articles. Footnote: Adapted From: (Moher et al. 2009)

the entire United States, including four being conducted in veterans (Bohnert et al. 2012; Bohnert et al. 2011; Seal et al. 2012; Zedler et al. 2014), and one focused on women in the general population (Mack 2013). Of the 17 studies conducted in the United States that focus on smaller geographic areas, two were located in New Mexico (Paulozzi et al. 2012; Centers for Disease Control and Prevention 2005), two were located in Utah (Centers for Disease Control Prevention 2005; Lanier et al. 2012), two were located in Washington State (Dunn et al. 2010; Centers for Disease Control Prevention 2009), two were located in West Virginia (Hall et al. 2008; Peirce et al. 2012), while the others evaluated the Appalachian counties of Kentucky (Havens et al. 2011a), Los Angeles (Silva et al. 2013), Boston (Bauer et al. 2016)), New York City (Silva et al. 2013; Cerdá et al. 2013; Brady et al. 2015), Colorado (Dilokthornsakul et al. 2016), North Carolina (Whitmire and Adams 2010), Oklahoma (Piercefield et al. 2010) and Oregon (Hartung et al. 2007). The time periods of the studies conducted in Washington State overlapped by 3 years, but each study contained data for a time period that did not overlap (Dunn et al. 2010; Centers for Disease Control Prevention 2009). Similarly, the studies in West Virginia overlap by 1 year, but one study examines all residents of the state and unintentional overdose decedents in 1 year (Hall et al. 2008), while the other evaluates residents of the state who received and filled a prescription for a controlled substance over a two and half year time period (Peirce et al. 2012). With the exception of California, Colorado, North Carolina, New York and Oregon, the majority of these locations had age-adjusted PDO death rates that were higher than the national rate (16.3 per 100,000 population) in 2015 , the latest year for which data were available (Rudd 2016; Hartung et al. 2007).

The outcomes evaluated in the 29 studies included morbidity and mortality measures. Drugs assessed in these studies were not specifically limited to prescription opioids. Ten of these studies focused on prescription opioid overdose (Bohnert et al. 2011; Dunn et al. 2010; Lanier et al. 2012; Gomes et al. 2011; Seal et al. 2012; Cerdá et al. 2013; Brady et al. 2015; Dilokthornsakul et al. 2016; Hartung et al. 2007), eight examined PDO (Centers for Disease Control and Prevention 2011; Coben et al. 2010; Silva et al. 2013; Mack 2013; Centers for Disease Control and Prevention 2005; Centers for Disease Control Prevention 2009; Peirce et al. 2012; Paulozzi et al. 2011), three examined overdose from both prescription and over-the-counter (OTC) medications (Bohnert et al. 2012; Hulse et al. 2001; Piercefield et al. 2010), one examined non-illicit drug 


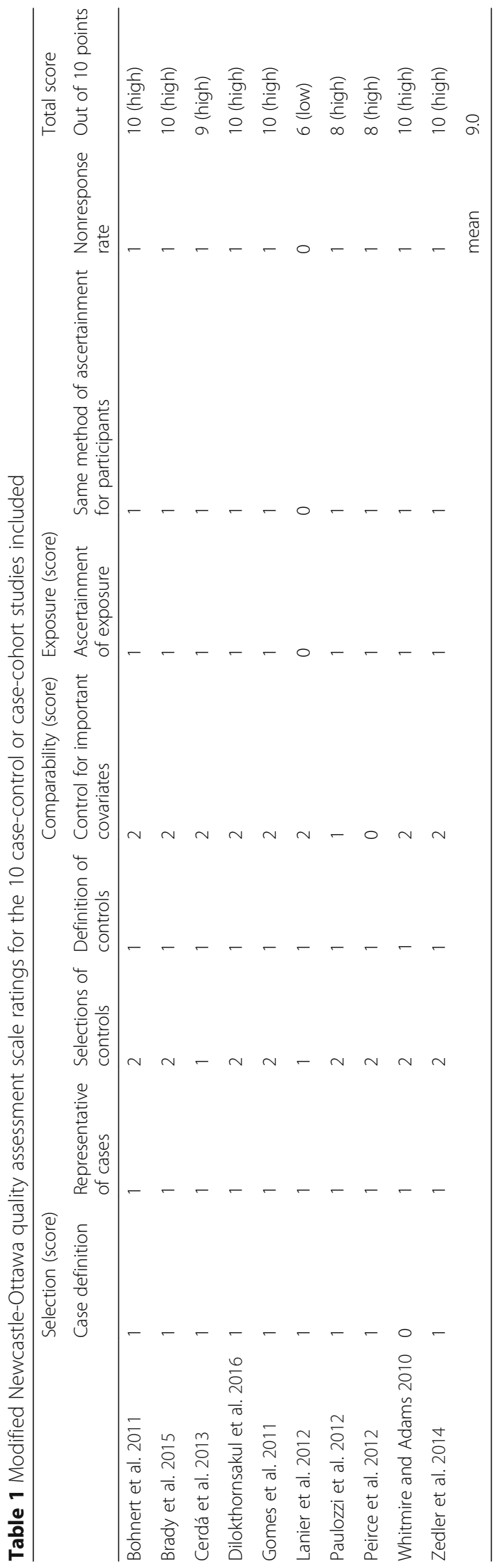


Table 2 Newcastle-Ottawa quality assessment scale ratings for the 7 cohort studies included

\begin{tabular}{|c|c|c|c|c|c|c|c|c|c|}
\hline & \multicolumn{4}{|l|}{ Selection } & \multirow{2}{*}{$\begin{array}{l}\text { Comparability } \\
\text { Comparability }\end{array}$} & \multicolumn{3}{|l|}{ Outcome } & \multirow{2}{*}{$\begin{array}{l}\text { Total score } \\
\text { Out of } 9 \\
\text { points }\end{array}$} \\
\hline & $\begin{array}{l}\text { Representative of } \\
\text { exposed cohort }\end{array}$ & $\begin{array}{l}\text { Selections of non } \\
\text { exposed cohort }\end{array}$ & $\begin{array}{l}\text { Assessment } \\
\text { of exposure }\end{array}$ & $\begin{array}{l}\text { Absence of } \\
\text { outcome at } \\
\text { start of study }\end{array}$ & & $\begin{array}{l}\text { Assessment of } \\
\text { outcome }\end{array}$ & $\begin{array}{l}\text { Follow-up period } \\
\text { ( } \geq 6 \text { months) }\end{array}$ & $\begin{array}{l}\text { Adequacy of } \\
\text { follow-up }\end{array}$ & \\
\hline $\begin{array}{l}\text { Bauer et al. } \\
2016\end{array}$ & 1 & 1 & 1 & 1 & 2 & 1 & 1 & 0 & 8 (high) \\
\hline $\begin{array}{l}\text { Bohnert et al. } \\
2012\end{array}$ & 1 & 1 & 1 & 1 & 2 & 1 & 1 & 0 & 8 (high) \\
\hline $\begin{array}{l}\text { Caudarella } \\
\text { et al. } 2016\end{array}$ & 1 & 1 & 1 & 1 & 2 & 1 & 1 & 1 & 9 (high) \\
\hline Dunn et al. 2010 & 1 & 1 & 1 & 1 & 2 & 1 & 1 & 0 & 8 (high) \\
\hline $\begin{array}{l}\text { Hartung et al. } \\
2007\end{array}$ & 1 & 1 & 1 & 1 & 2 & 1 & 1 & 0 & 8 (high) \\
\hline Seal et al. 2012 & 1 & 1 & 1 & 1 & 2 & 1 & 1 & 0 & 8 (high) \\
\hline \multirow{2}{*}{$\begin{array}{l}\text { Turner and } \\
\text { Liang } 2015\end{array}$} & 1 & 1 & 1 & 1 & 2 & 1 & 1 & 0 & 8 (high) \\
\hline & & & & & & & & mean & 8.1 \\
\hline
\end{tabular}

overdose (Centers for Disease Control Prevention 2005) including prescription drugs, OTC medications, and alcohol, and the remaining eight examined unintentional overdose deaths-with some indication of prescription drug use (Havens et al. 2011a; Paulozzi et al. 2012; Caudarella et al. 2016; Zedler et al. 2014; Hall et al. 2008; Bauer et al. 2016; Whitmire and Adams 2010; Turner and Liang 2015). Of the 29 studies, ten (Coben et al. 2010; Dunn et al. 2010; Havens et al. 2011a; Silva et al. 2013; Hulse et al. 2001; Seal et al. 2012; Zedler et al. 2014; Dilokthornsakul et al. 2016; Hartung et al. 2007; Turner and Liang 2015) examined nonfatal overdose. One study examined all fatal poisonings and all intents, including suicide and homicide (Rudd et al. 2016).

\section{Identification of risk markers}

Risk marker information was extracted and evaluated for the most commonly examined variables across the 29 eligible studies: sex, age, white race, psychiatric disorders, SUDs, and urban/rural residence. Specifically, 21 studies examined sex, 13 studies examined age as a categorical variable, 14 studies examined race, 11 studies examined psychiatric disorders, 10 studies examined SUDs and five studies examined urban/rural residence.

\section{Synthesis and findings of the quantitative review}

Sex

Most studies found that the proportion of males who overdosed was greater than the proportion of females

Table 3 Modified Newcastle-Ottawa quality assessment scale ratings for the 12 cross-sectional studies

\begin{tabular}{|c|c|c|c|c|c|c|c|c|}
\hline & $\begin{array}{l}\text { Representativeness } \\
\text { of sample }\end{array}$ & $\begin{array}{l}\text { Sample } \\
\text { size }\end{array}$ & Non-respondents & $\begin{array}{l}\text { Ascertainment of } \\
\text { the risk marker }\end{array}$ & Comparability & $\begin{array}{l}\text { Ascertainment } \\
\text { of the outcome }\end{array}$ & $\begin{array}{l}\text { Statistical } \\
\text { test }\end{array}$ & $\begin{array}{l}\text { Out of } 10 \\
\text { points }\end{array}$ \\
\hline CDC Medicaid. 2009 & 1 & 0 & 0 & 1 & 0 & 2 & 1 & 5 (low) \\
\hline $\begin{array}{l}\text { CDC Non-illicit Drugs } \\
\text { Utah } 2005\end{array}$ & 1 & 0 & 0 & 1 & 0 & 2 & 1 & 5 (low) \\
\hline $\begin{array}{l}\text { CDC Prescription opioid } \\
\text { pain relievers. } 2011\end{array}$ & 1 & 0 & 0 & 1 & 1 & 2 & 1 & 6 (low) \\
\hline $\begin{array}{l}\text { CDC Urbanization, } \\
\text { New Mexico, } 2005\end{array}$ & 1 & 0 & 0 & 2 & 2 & 2 & 1 & 8 (high) \\
\hline Coben et al. 2010 & 1 & 0 & 0 & 1 & 1 & 2 & 1 & 6 (low) \\
\hline Havens et al. 2011a & 1 & 0 & 0 & 1 & 2 & 1 & 1 & 5 (low) \\
\hline Hall et al. 2008 & 1 & 0 & 0 & 1 & 0 & 2 & 1 & 5 (low) \\
\hline Hulse et al. 2001 & 0 & 0 & 0 & 1 & 0 & 2 & 1 & 4 (low) \\
\hline Mack 2013 & 1 & 0 & 0 & 1 & 0 & 2 & 1 & 5 (low) \\
\hline Piercefield et al. 2010 & 1 & 0 & 0 & 1 & 0 & 2 & 1 & 5 (low) \\
\hline Rudd et al. 2016 & 1 & 0 & 0 & 1 & 1 & 2 & 1 & 6 (low) \\
\hline \multirow[t]{2}{*}{ Silva et al. 2013} & 1 & 0 & 0 & 0 & 2 & 1 & 1 & 5 (low) \\
\hline & & & & & & & mean & 5.4 \\
\hline
\end{tabular}


Table 4 Risk markers and outcomes of studies evaluating prescription drug overdose

\begin{tabular}{|c|c|c|c|}
\hline First author, year & Risk markers and exposures assessed & Outcome & Sample size \\
\hline Bauer et al. 2016 & $\begin{array}{l}\text { Age, sex, race/ethnicity, veteran, location of } \\
\text { death, autopsy performed }\end{array}$ & Drug overdose death & 28,033 \\
\hline Bohnert et al. $2011^{\mathrm{a}}$ & $\begin{array}{l}\text { Sex, age, race, clinical diagnoses, comorbid } \\
\text { conditions, as well as opioid dose and schedule }\end{array}$ & $\begin{array}{l}\text { Unintentional prescription opioid overdose } \\
\text { (ICD-10 X42, X44, Y12 or Y14 in combination } \\
\text { with T40.2) }\end{array}$ & 155,434 \\
\hline Bohnert et al. $2012^{a}$ & $\begin{array}{l}\text { Sex, age, Charlson comorbidities, psychiatric diagnoses, } \\
\text { substance use disorders, alcohol use disorders, other } \\
\text { specific drug use or mental health disorders }\end{array}$ & $\begin{array}{l}\text { Death by accidental medication overdose was an } \\
\text { accidental death with an underlying cause of } \\
\text { death coded as ICD-10 codes X40-X45 due in part } \\
\text { or whole to prescription or over the counter } \\
\text { medications (ICD-10 codes T36.0-T39.9, T40.2-T40.4, } \\
\text { and T42.0-T50.9) }\end{array}$ & $3,291,891$ \\
\hline Brady et al. 2015 & ED utilization, age, sex, race, clinical characteristics & Prescription drug overdose death & 5464 \\
\hline Caudarella et al. 2016 & Age, gender, ethnicity, homelessness, incarceration, & Overdose mortality & 2317 \\
\hline
\end{tabular}

A Washington state resident whose death certificate

CDC Medicaid. 2009 Sex, age, Medicaid had a manner of death listed as "accidental" or "natural" and one or more contributing causes coded as ICD-10 (T40.0-T40.6 and F11) and specific words compatible with acute drug intoxication recorded in any death field and a prescription opioid in any of the cause of death fields

\author{
CDC Non-illicit Drugs Sex, age, area of residence \\ Utah $2005^{\mathrm{b}}$ \\ CDC Prescription opioid Sex, age, race \\ pain relievers. 2011
}

$\begin{array}{ll}\text { CDC Urbanization, } & \text { Urbanization } \\ \text { New Mexico, 2005 } & \\ \text { Cerdá et al. 2013 } & \text { Sex, age, race } \\ \text { Coben et al. } 2010 & \text { Sex and age }\end{array}$

Dilokthornsakul et al. 2016

Dunn et al. 2010

Gomes et al. $2011^{c}$

Hall et al. 2008

Hartung et al. 2007

Havens et al. 2011a Hulse et al. 2001
Type of long acting opioid (Methadone, Oxycodone, Fentanyl, Morphine) Sex, age, race, psychiatric comorbidities, substance use

Sex, age, mean morphine dose equivalents, methadone use, chronic opioid use, pain diagnosis, comorbidities, history of other medication use

Sex, age, history of depression, history of substance abuse, opioid dose, any opioid use

No. of pharmacies dispensing opioids, daily dose of opioids (>200 mg MME)

Sex, age, marital status and highest education Sex
Non-illicit drug poisoning death

Prescription drug overdose deaths (with underlying causes of deaths listed as ICD-10 codes X40-X44, X60-X64, X85 or Y10-Y14 and having T36-T39, T40.2-T40.4, T41-T43.5, and T43.7-T50.8) as contributing causes

Unintentional poisoning deaths from prescription drugs (i.e. methadone, other opioid painkiller, tranquillizer/muscle relaxant, antidepressant, barbiturate, or other prescription drug)

Analgesic overdose fatalities (ICD-10 X40-X44, T40.0-T40.2)

Hospitalizations for poisoning by prescription opioids, sedatives and tranquilizers (ICD-9965.02, 965.09, 965.5, 965.8, 967.0, 969.4, 969.5, 967.8, and 967.9.) Poisonings were classified as unintentional if there was an E-code present in the E850-E858 range (accidental poisonings by drugs, medicinal substances, and biologicals)

$\geq 1$ medical claim for an emergency department visit or a hospitalization associated with an opioid overdose

Opioid-related overdose death, or non-fatal event defined as definite or probable opioid-related overdose

Opioid-related death

Unintentional drug overdose deaths that involved prescription pharmaceuticals. This excluded those overdoses due solely to illicit drugs, over-the-counter products, or alcohol.

Administrative claims for an opioid-related serious adverse event, ED encounter or hospitalization for opioid-related adverse event (CPT code $99281-99285$ or 99,288 or ED revenue center codes of $45 \times$ or 981 with ICD-9965.0x), opioid poisoning (ICD-9965.0X), or overdose symptoms (ICD-9 codes 780.0x, 78.07x, 418.81, 518.82, 564.0x)

Non-fatal overdose

Hospitalization for prescription /over the counter drugs
$304,093,966$ 
Table 4 Risk markers and outcomes of studies evaluating prescription drug overdose (Continued)

\begin{tabular}{|c|c|c|c|}
\hline Lanier et al. 2012 & $\begin{array}{l}\text { Sex, age, race, marital status, body mass index, } \\
\text { uninsured, education, employment status, smoking } \\
\text { status, residence in an urban county, military service }\end{array}$ & Death from prescription opioids & 1562 \\
\hline Mack 2013 & Age and race & $\begin{array}{l}\text { Prescription drug overdose deaths (with underlying } \\
\text { causes of deaths listed as ICD-10 codes X40-X44, X60-X64, } \\
\text { X85 or Y10-Y14 and having T36-T39, T40.2-T40.4, T41-T43.5, } \\
\text { and T43.8-T50.8) as contributing causes }\end{array}$ & $157,237,928$ \\
\hline Paulozzi et al. 2012 & Sex, age, prescription history & Death from unintentional drug overdose & 6293 \\
\hline Peirce et al. 2012 & Prior doctor and or pharmacy shopping & Controlled substance-related death & $1,049,903$ \\
\hline Piercefield et al. $2010^{d}$ & Sex, age, race and urban/rural & Medication overdose deaths & $3,540,517$ \\
\hline Rudd et al. 2016 & Sex, age, race & $\begin{array}{l}\text { Prescription drug overdose deaths (with underlying } \\
\text { causes of deaths listed as ICD-10 codes X40-X44, } \\
\text { X60-X64, X85 or Y10-Y14 and having T36-T39, T40.2-T40.4, } \\
\text { T41-T43.5, and T43.7-T50.8) as contributing causes }\end{array}$ & $641,538,924$ \\
\hline Seal et al. $2012^{a}$ & $\begin{array}{l}\text { Opioid use, post-traumatic stress disorder (PTSD), } \\
\text { PTSD with or without other mental health disorders }\end{array}$ & $\begin{array}{l}\text { Opioid-related accidents and overdoses (ICD-9 codes: } \\
\text { 965.00, 965.01, 965.02,965.09, E850.0, E850.1, E850.2, } \\
\text { E935.0, E935.1, and E935.2) }\end{array}$ & 141,030 \\
\hline Silva et al. 2013 & Sex, race, psychiatric care, substance use & $\begin{array}{l}\text { Non-fatal overdose on prescription opioids and/or } \\
\text { tranquilizers }\end{array}$ & 596 \\
\hline Turner and Liang 2015 & $\begin{array}{l}\text { Sex, age, US region, clinical conditions, mental health } \\
\text { and substance use disorders, }\end{array}$ & Any drug overdose event & 206,869 \\
\hline $\begin{array}{l}\text { Whitmire and Adams } \\
2010^{d}\end{array}$ & $\begin{array}{l}\text { Eligibility category, race, residence, specific disorders, } \\
\text { drug claims }\end{array}$ & Unintentional overdose death (ICD-10 X40-X49) & 2801 \\
\hline Zedler et al. 2014 & $\begin{array}{l}\text { Age, sex, race/ethnicity, marital status, BMI, US Census } \\
\text { region, comorbidities, opioid use, all-cause health care } \\
\text { utilization (ED visits) }\end{array}$ & $\begin{array}{l}\text { Occurrence of serious opioid-related toxicity or overdose } \\
\text { as defined by listed ICD-9-CM and CPT codes }\end{array}$ & 8987 \\
\hline
\end{tabular}

MMEs morphine milligram equivalents, CPT current procedural terminology, ICD-9 international classification of diseases, 9th revision, ICD-10 international classification of diseases, 10th revision, CS controlled substances, OME office of the medical examiner

${ }^{\mathrm{a}}$ Studies are not independent

bInformation refers to deaths occurring between 1999 and 2003

Information refers to deaths occurring between 2004 and 2006

${ }^{\mathrm{d}}$ Matching variables not included in risk markers

who overdosed. However, there was some variation in effect estimates by sex across studies. Twelve studies showed that males were at statistically significant increased risk for PDO (Centers for Disease Control and Prevention 2011; Coben et al. 2010; Centers for Disease Control Prevention 2005; Bohnert et al. 2012; Paulozzi et al. 2012; Lanier et al. 2012; Centers for Disease Control Prevention 2009; Hall et al. 2008; Bauer et al. 2016; Brady et al. 2015; Piercefield et al. 2010; Rudd et al. 2016), six studies showed that there were no statistically significant differences between sexes (Bohnert et al. 2011; Dunn et al. 2010; Havens et al. 2011a; Silva et al. 2013; Caudarella et al. 2016; Zedler et al. 2014) and three studies showed that females were at increased risk for PDO (Hulse et al. 2001; Cerdá et al. 2013; Turner and Liang 2015). Overall, the random effects model showed a statistically significant increased risk for males as compared to females (summary odds ratio $(\mathrm{SOR})=1.33$, 95\% confidence interval $(\mathrm{CI}) 1.17$, 1.51) (Fig. 2). The results of the "one study removed" analysis indicated that the SOR was robust, as SOR from random effects models ranged from 1.29 to 1.38. Rosenthal's classic fail safe $\mathrm{N}$, the number of new, unpublished, or null studies that would be needed to make the overall finding not significant, was 2313 (Persaud 1996).

\section{Age}

The variation in the effect estimates across studies comparing $<25,35-44,45-54$, and $\geq 55$ years to $25-34$ years (reference group) showed that the 35-44 and 44-54 year age groups were most often at the greatest risk for overdose (Figs. 3 and 4). All studies included in Figs. 3 and 4 examined fatal overdoses. For the study conducted in Washington State (Centers for Disease Control Prevention 2009), both the Medicaid population and the total population distribution of overdoses were examined, even though the age distribution of overdose was similar in the total population and the Medicaid population.

\section{Race}

Of the 14 studies that examined race as a risk marker, 11 showed that Whites were at increased risk for PDO as compared to all other racial groups combined (Fig. 5). The overall SOR showed that Whites had statistically significant increased risk for PDO when compared to other racial groups combined (SOR 2.28, 95\% CI 1.93, 2.70). Results of the "one study removed analysis" showed SOR from random effects models ranging from 2.13 to 2.42 . Rosenthal's classic fail safe N was 3785 (Persaud 1996). 


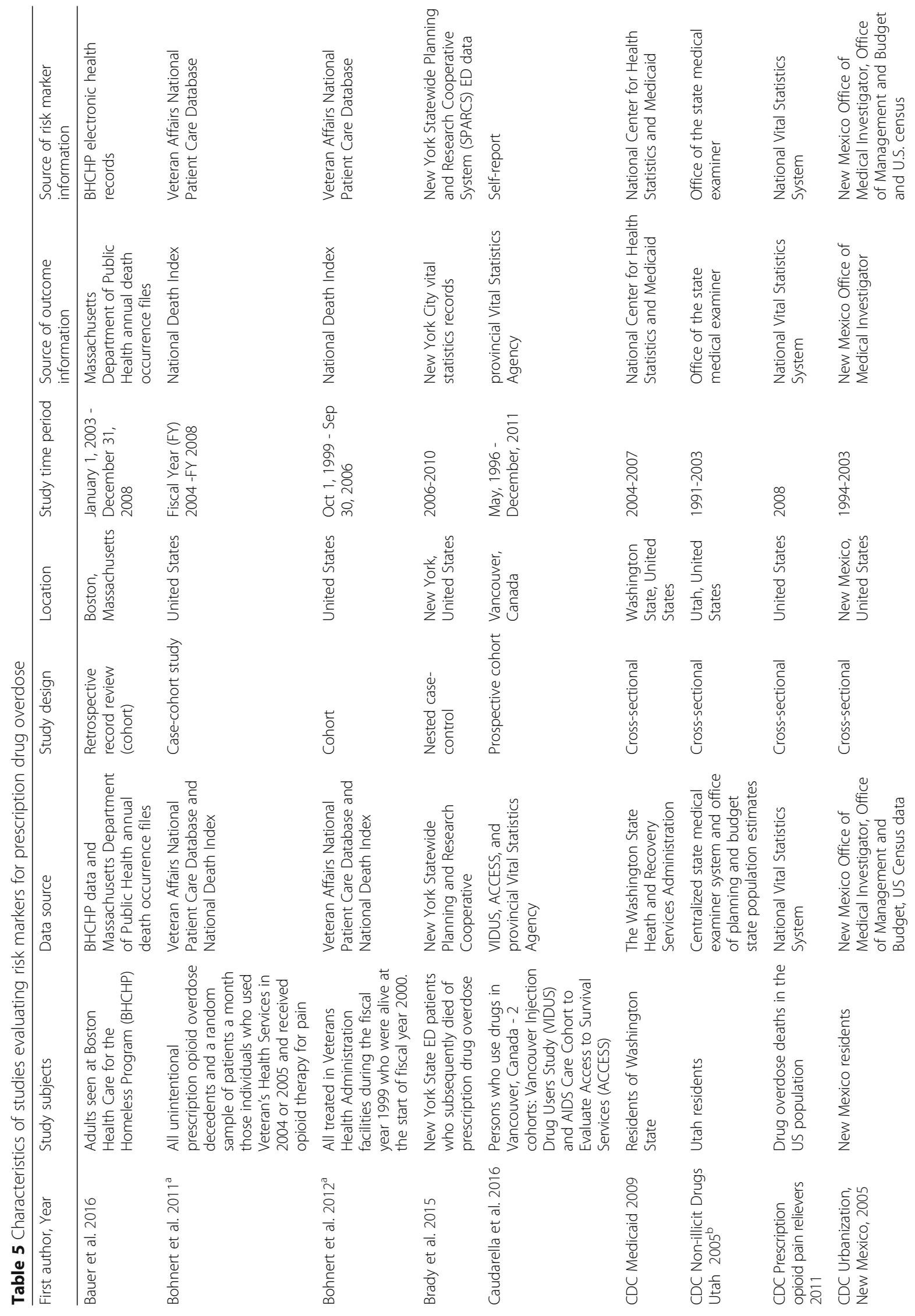




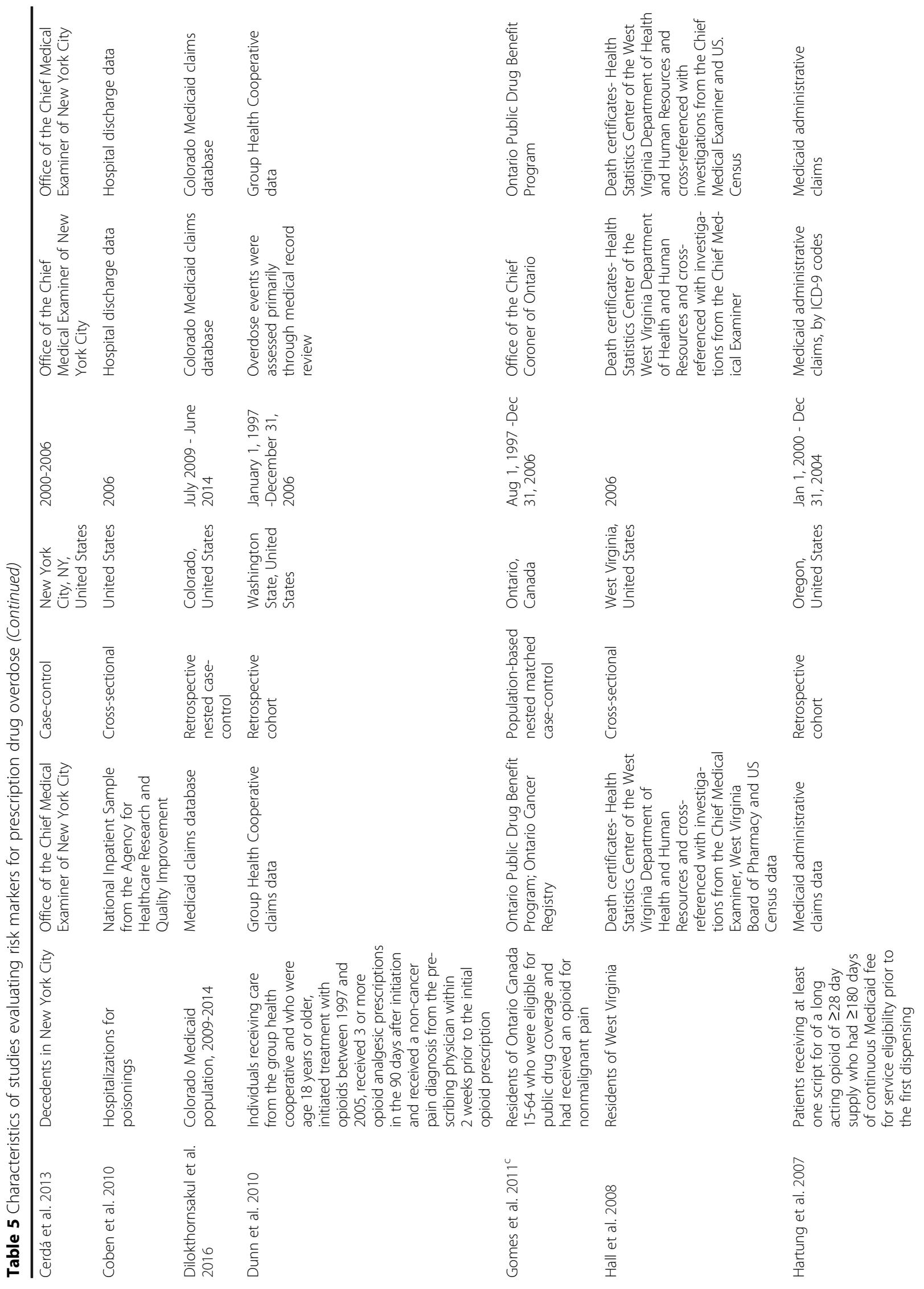




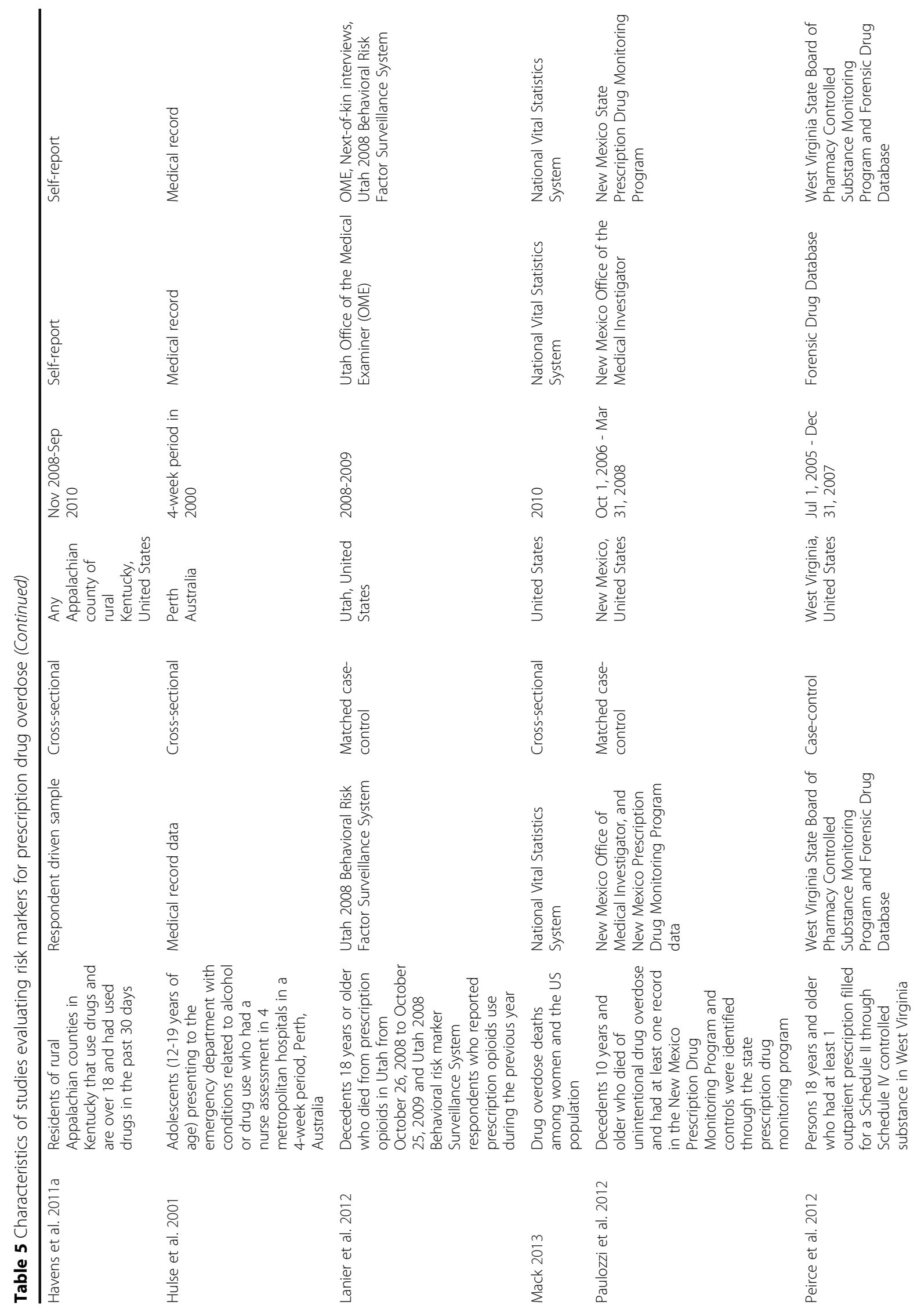




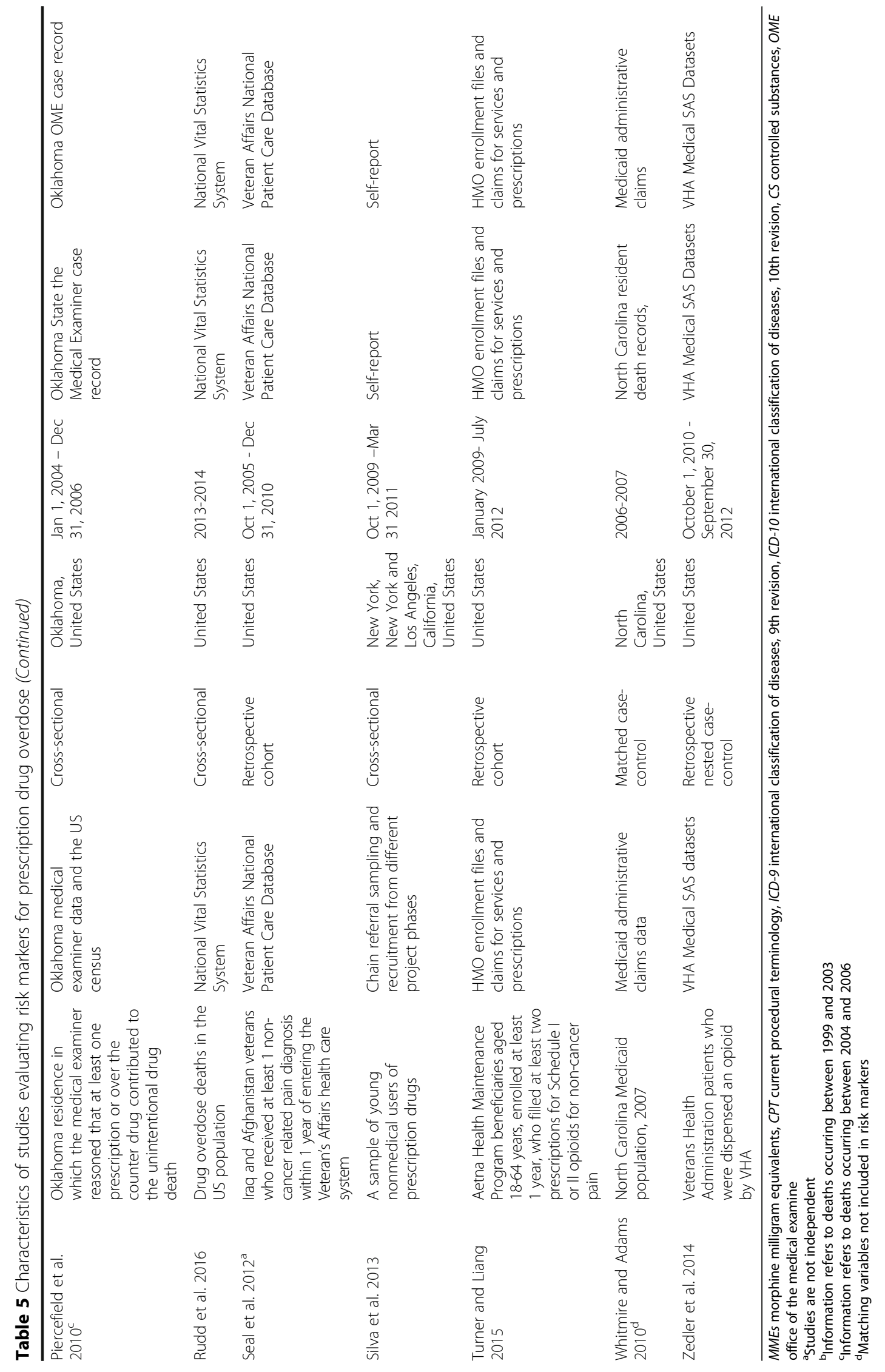




$\begin{array}{cl}\text { Model } & \text { Study name } \\ & \\ & \text { Bauer et al. 2016 } \\ & \text { Bohnert et al. 2011 } \\ & \text { Bohnert et al. 2012 } \\ & \text { Brady et al. 2015 } \\ & \text { Caudarella et al. 2016 } \\ & \text { CDC Medicaid, 2009 Medic aid Population } \\ & \text { CDC Medicaid, 2009 Total Population } \\ & \text { CDC Non-ilicit Drugs Utah, 2005 } \\ & \text { CDC Prescription pain relievers, 2011 } \\ & \text { Cerda et al. 2013 } \\ & \text { Coben et al. 2010 } \\ & \text { Dunn et al. 2010 } \\ & \text { Hall et al. 2008 } \\ & \text { Havens et al. 2011 } \\ & \text { Hulse et al. 2001 } \\ & \text { Lanier et al. 2012 } \\ & \text { Paulozzi i. al. 2012 } \\ & \text { Piercefield et al. 2010 } \\ & \text { Rudd et al. 2016 } \\ & \text { Siliva et al. 2013 } \\ & \text { Turner \& Liang 2015 } \\ & \text { Zedler et al. 2014 } \\ \text { Fixed } & \\ \text { Random } & \\ & \end{array}$

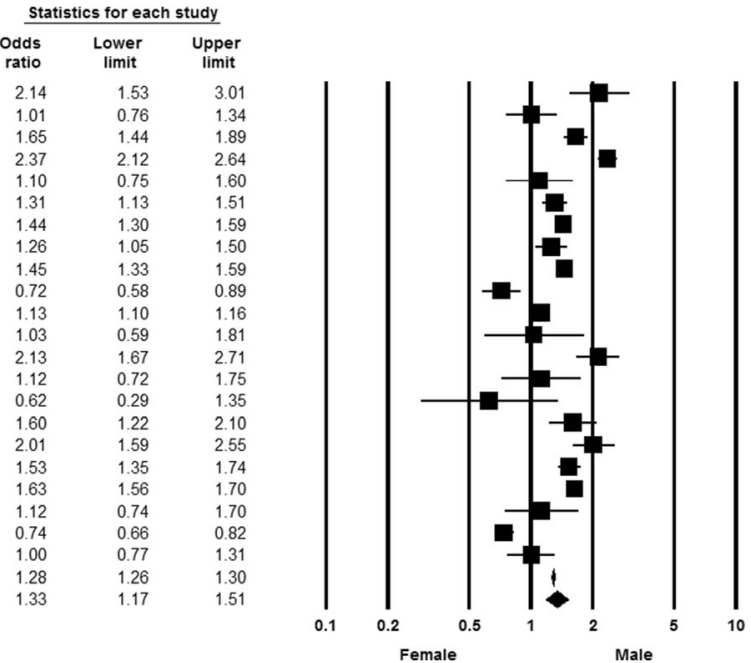

Fig. 2 Forest plot, summary odds ratio and 95\% confidence of prescription drug overdose with sex. The size of each square is proportional to the relative weight that each study contributed to the summary odds ratio. The summary odds ratio is indicated by the diamond. Horizontal bars indicate the 95\% confidence interval. Heterogeneity: Q statistic: 553.2, $\mathrm{df}=21, P<0.0001 . \mathrm{I}^{2}=96.2$. Footnote: The Bohnert et al. (2011) and Bohnert et al. (2012) papers arose from the same underlying population. In the CDC Medicaid 2009 study, the Medicaid population is a subgroup of the total population. Note: The standard errors for the CDC Prescription opioid pain relievers 2011 and Rudd et al. (2016) studies may be smaller than what was used to calculate the confidence intervals. The sample size for this study exceeded the maximum allowed by Comprehensive Meta-Analysis software, so one digit was removed from each component of the odds ratio

\section{Psychiatric disorders}

In each of the 11 studies that examined psychiatric disorders, the incidence of drug overdose in individuals with psychiatric disorders was higher than in individuals without psychiatric disorders (Tables 6 and 7). However, these studies used varying definitions of conditions considered to be psychiatric disorders. The overall SOR showed that individuals with psychiatric disorders have a statistically significant increased risk for PDO compared with those who do not have psychiatric disorders (SOR $=3.94,95 \%$ CI 3.09, 5.01). The results of the "one study removed analysis" showed SOR from random effects models ranging from 3.60 to 4.11. Rosenthal's classic fail safe $\mathrm{N}$ was 7396.

\section{SUDs}

SUDs were found to be associated with an increased risk of PDO in each of the 10 studies that examined this risk marker. Although the definition of SUDs used in these studies varied, the results were generally consistent (Fig. 6). Overall, the SOR of PDO associated with SUDs was 5.24 (95\% CI 3.53, 7.76). The results of the "one study removed analysis" showed that random effects SORs ranged from 4.53 to 5.92 . Rosenthal's classic fail safe $\mathrm{N}$ was 9465 .

\section{Rural residence}

The five studies that examined the association rural/ urban residence with the risk of PDO reported conflicting results. The estimated ORs of PDO associated with rural areas compared to urban areas varied considerably across studies (Fig. 7). The random effects SOR of PDO associated with rural residence was not statistically significant $(\mathrm{SOR}=0.93,95 \%$ CI $0.72,1.19)$.

\section{Heterogeneity}

Heterogeneity in effect estimates was assessed with the $\mathrm{Q}$ and $\mathrm{I}^{2}$ statistics and was found to be significant for each of the six risk markers examined (Figs. 2, 3, 5, 6, 7 and 8). Heterogeneity in effect estimates persisted across each of the six risk markers examined when stratifying by study design, quality assessment score, type of substances used, and whether the study examined fatal overdose or fatal and non-fatal overdose (not shown).

\section{Discussion}

Given the current drug overdose crisis in the United States, it is important to understand risk markers for PDO and understand how findings may vary across studies. This meta-analysis summarizes published literature on PDO for six risk markers that were most frequently assessed in the literature: male sex, age 35-44 years, white race, comorbid psychiatric disorder diagnosis, comorbid diagnosis of a SUD and urban/rural area of residence. While, none of the risk markers identified in this systematic review are easily modifiable, understanding them may help identify individuals at heightened risk for PDO.

While males are at greater risk for PDO on average, sex is a relatively weak and inconsistent risk marker resulting in an overall $20 \%$ increase in PDO in men. Six 


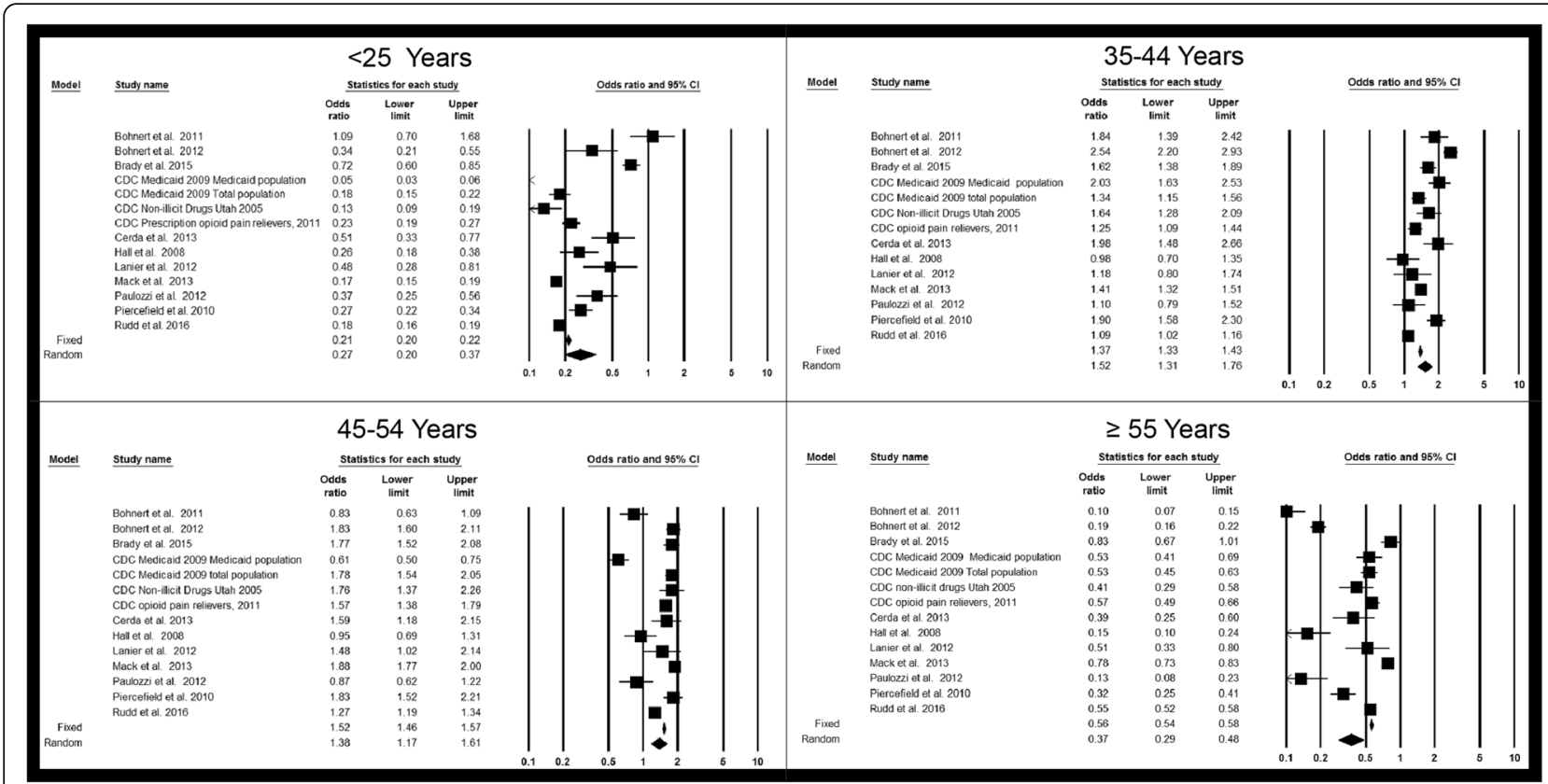

Fig. 3 Forest plot, summary odds ratio and 95\% confidence of prescription drug overdose with age. For all plots, 25-34 years is the reference group. The size of each square is proportional to the relative weight that each study contributed to the summary odds ratio. The summary odds ratio is indicated by the diamond. Horizontal bars indicate the $95 \%$ confidence interval. <25 years vs. 25-34 years Heterogeneity: Q statistic: 407.8 , $\mathrm{df}=13, P<0.0001 .\left.\right|^{2}=96.8 ; 35-44$ years vs. $25-34$ years Heterogeneity: $\mathrm{Q}$ statistic: $172.0, \mathrm{df}=13, P<0.0001 . \mathrm{I}^{2}=92.4 ; 45-54$ years vs. $25-34$ years Heterogeneity: $Q$ statistic: $213.0, d f=13, P<0.0001 .1^{2}=93.9 ; \geq 55$ years vs. 25-34 years Heterogeneity: $Q$ statistic: $440.0, d f=13, P<0.0001$. $I^{2}=$ 97.0. Footnote: The standard errors for the CDC Prescription opioid pain relievers 2011, Mack (2013) and Rudd et al. (2016) studies may be smaller than what was used to calculate the confidence intervals. The sample size for this study exceeded the maximum allowed by Comprehensive Meta-Analysis software, so one digit was removed from each component of the odds ratio

studies did not find any increase in risk for PDO for males as compared to females (Bohnert et al. 2011; Dunn et al. 2010; Havens et al. 2011a; Silva et al. 2013; Caudarella et al. 2016; Zedler et al. 2014). Three studies found the females were at increased risk for PDO, which may be a consequence of the study populations

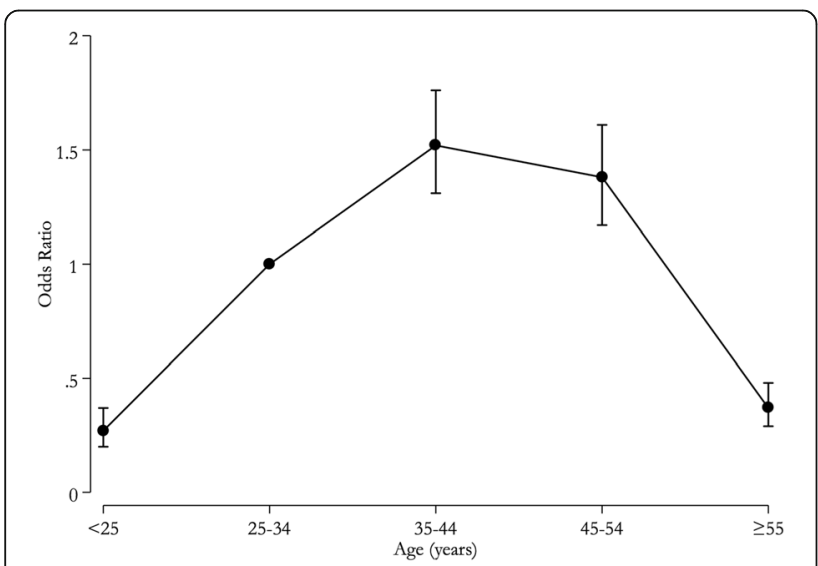

Fig. 4 Line graph of summary odds ratios of prescription drug overdose associated with age. Error bars indicate the 95\% confidence interval. $<25$ years vs. $25-34$ years examined in these two studies (Hulse et al. 2001; Cerdá et al. 2013; Turner and Liang 2015). First, Cerdá et al. (2013) found that in comparison to females, males in New York City appear to be at greater risk for other accidental death relative to opioid analgesic PDO. The study's finding of increased risk for unintentional opioid analgesic PDO in women in New York City may be related to the authors' choice of reference group (nonoverdose-related fatal accidents). It is known that overall in the United States males are at greater risk for accidental death than women (Waldron et al. 2005). Thus, men in the reference group have a lower risk of fatal overdose than the general population as well as those experiencing non-accidental death, resulting in higher estimates of gender differences (Sorenson 2011; Insurance Institute for Highway Safety 2017). Second, Hulse et al. (2001) studied a small group of adolescents seeking treatment in the ED for alcohol or drug related ailments and found females have a greater risk for non-fatal prescription drug related overdose in comparison to males. The Hulse et al. finding is consistent with literature on rates of hospitalization and ED visits for prescription drug use and non-fatal poisoning which show women are more likely than men to utilize care for 


\begin{tabular}{rlccc} 
Model & Study name & \multicolumn{3}{c}{ Statistics for each study } \\
\cline { 3 - 5 } & $\begin{array}{c}\text { Odds } \\
\text { ratio }\end{array}$ & $\begin{array}{c}\text { Lower } \\
\text { limit }\end{array}$ & $\begin{array}{c}\text { Upper } \\
\text { limit }\end{array}$ \\
& Bauer et al. 2016 & 2.84 & 2.14 & 3.78 \\
& Bohnert et al. 2011 & 1.97 & 1.63 & 2.39 \\
& Brady et al. 2015 & 2.73 & 2.43 & 3.06 \\
& Caudarella et al. 2016 & 1.03 & 0.72 & 1.48 \\
& CDC Prescription opioid pain relievers, 2011 & 2.62 & 2.24 & 3.06 \\
& Cerda et al. 2013 & 2.69 & 2.19 & 3.30 \\
& Havens et al. 2011 & 0.39 & 0.17 & 0.89 \\
& Lanier et al. 2012 & 3.90 & 1.57 & 9.69 \\
& Mack et al. 2013 & 2.94 & 2.44 & 3.55 \\
& Piercefield te al. 2010 & 3.12 & 2.46 & 3.96 \\
& Rudd et al. 2016 & 2.23 & 2.11 & 2.35 \\
& Silva et al. 2013 & 1.03 & 0.71 & 1.52 \\
& Whitmire et al. 2010 & 7.16 & 5.07 & 10.12 \\
Fixed & Zedler et al. 2014 & 1.69 & 1.45 & 1.97 \\
Random & & 2.32 & 2.23 & 2.41 \\
& & 2.28 & 1.93 & 2.70 \\
& & & &
\end{tabular}

Odds ratio and $95 \% \mathrm{Cl}$
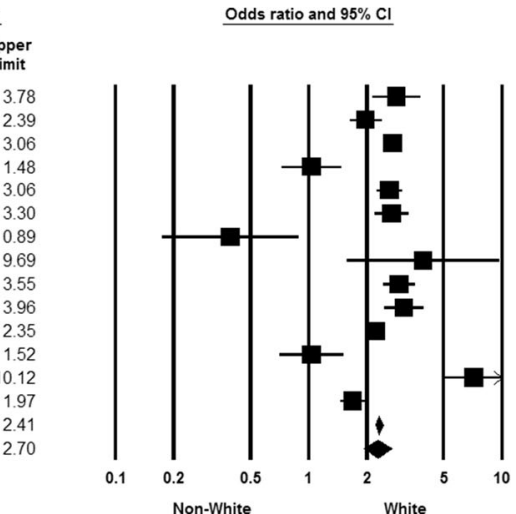

Fig. 5 Forest plot, summary odds ratio and 95\% confidence of prescription drug overdose with white race. The size of each square is proportional to the relative weight that each study contributed to the summary odds ratio. The summary odds ratio is indicated by the diamond. Horizontal bars indicate the $95 \%$ confidence interval. Heterogeneity: Q statistic: $144.2, \mathrm{df}=13, P<0.0001 . \mathrm{I}^{2}=91.0$. Footnote: The standard errors for the CDC Prescription opioid pain relievers 2011, Mack (2013) and Rudd et al. (2016) studies may be smaller than what was used to calculate the confidence intervals. The sample sizes for these studies exceeded the maximum allowed by Comprehensive Meta-Analysis software, so one digit was removed from each component of the odds ratios

prescription drug misuse or non-fatal poisoning (Cai et al. 2010; Unick et al. 2013; Xiang et al. 2012). Finally, Turner et al. studied HMO beneficiaries and note that they may miss deaths occurring out of network or outpatient deaths. Women in the United States are more healthseeking than men and hospitalization for PDO is higher for women than for men, which may explain the increased risk for PDO in women compared to men observed in this study (Coben et al. 2010; Turner and Liang 2015).

Understanding the relationship between age and PDO is complicated by the fact that many studies examine different age categories. Increased risk for overdose is highest in the 35-44 age group, which in part may result from a cohort effect arising from the aging baby-boomer generation (Miech et al. 2011). However, this review did not specifically assess birth cohort as a risk marker. Additionally, age and physical condition affect one's ability to metabolize drugs (Smith 2009). Several studies have posited on the negative long-term implications of nonmedical use of prescription drugs in adolescents and young adults, including greater risk for dependence and bearing children dependent on prescription drugs (Whiteside et al. 2013; Patrick et al. 2012; Compton and Volkow 2006a, 2006b).

Whites have higher fatal and non-fatal PDO rates than other races. While the other studies included in this meta-analysis evaluated risk for fatal PDO, the only study that did not find that Whites were at increased risk for overdose evaluated self-reported nonfatal overdose incidents (Havens et al. 2011a). This study of nonfatal overdose incidents (Havens et al. 2011a) also used respondent-driven sampling - a method for sampling hard-to-reach populations - which may have resulted in a sample that is more homogeneous than would be obtained with traditional sampling methods (Havens et al. 2011a; Heckathorn 1997). Other studies have found that White race is associated with an increased risk for alcohol dependence, and heroin (Hasin et al. 2007; Woerle et al. 2007; Calcaterra et al. 2013). There are other reasons why non-Whites may be at lower risk for overdose related to differences in treatment for pain in White and non-White patients. It has been found that Black patients are less likely to be assessed and treated for pain than White patients (Hoffman et al. 2016). In survey respondents, this under-treatment for pain in Black patients has been linked to inaccurate beliefs among medical students and residents that Blacks patients experience less pain than White patients due to false assumptions about biological differences (Hoffman et al. 2016). Even when assessed for pain and being prescribed pain medication, surveys of pharmacies in New York City indicate that pharmacies in non-White neighborhoods were less likely to stock prescription opioid medications than pharmacies in White neighborhoods (Green et al. 2005; Singhal et al. 2016; Morrison et al. 2000). Decreased access to and availability of prescription opioids to non-White patients in comparison to White patients may translate to less prescription opioid use and less risk of PDO.

Across studies, this review found that patients with psychiatric disorders were at increased risk of PDO. There are many reasons that patients with psychiatric disorders are at increased risk for PDO. First, patients with psychiatric disorders are often prescribed 
Brady et al. Injury Epidemiology (2017) 4:24

Page 16 of 24

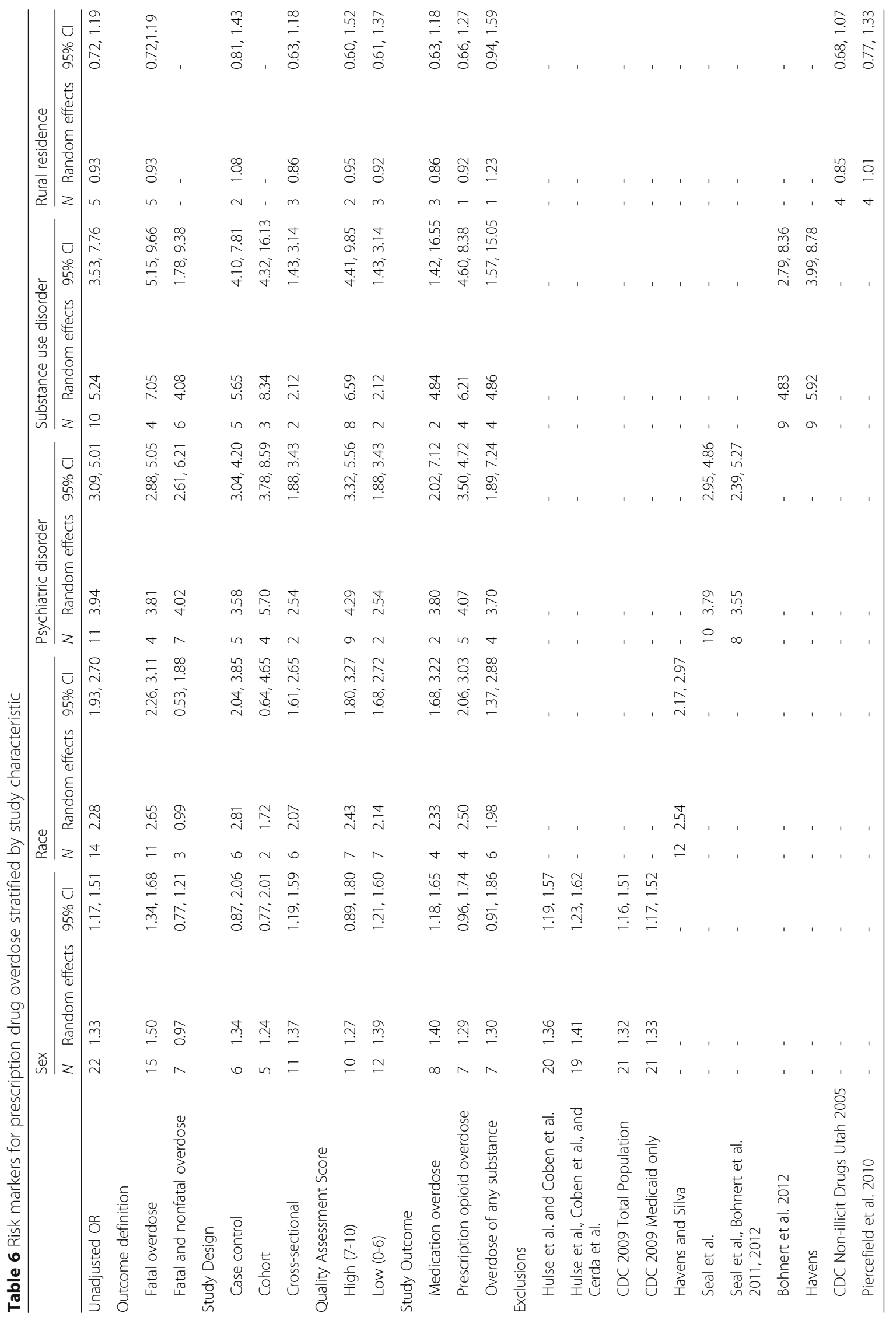


Table 7 Risk markers for prescription drug overdose stratified by study characteristics

\begin{tabular}{|c|c|c|c|c|c|c|c|c|c|c|c|c|}
\hline & \multicolumn{3}{|c|}{ Age $<25$} & \multicolumn{3}{|c|}{ Age $35-44$} & \multicolumn{3}{|c|}{ Age $45-54$} & \multicolumn{3}{|c|}{ Age 55 and older } \\
\hline & $N$ & $\begin{array}{l}\text { Random } \\
\text { effects }\end{array}$ & $95 \% \mathrm{Cl}$ & $N$ & $\begin{array}{l}\text { Random } \\
\text { effects }\end{array}$ & $95 \% \mathrm{Cl}$ & $N$ & $\begin{array}{l}\text { Random } \\
\text { effects }\end{array}$ & $95 \% \mathrm{Cl}$ & N & $\begin{array}{l}\text { Random } \\
\text { effects }\end{array}$ & $95 \% \mathrm{Cl}$ \\
\hline Unadjusted OR & 14 & 0.27 & $0.20,0.37$ & 14 & 1.52 & $1.31,1.76$ & 14 & 1.38 & $1.18,1.61$ & 14 & 0.37 & $0.29,0.48$ \\
\hline \multicolumn{13}{|l|}{ Outcome definition } \\
\hline Fatal overdose & - & - & - & - & - & - & - & - & - & - & - & - \\
\hline Fatal and nonfatal overdose & - & - & - & - & - & - & - & - & - & - & - & - \\
\hline \multicolumn{13}{|l|}{ Study Design } \\
\hline Case control & 5 & 0.60 & $0.43,0.83$ & 5 & 1.54 & $1.26,1.88$ & 5 & 1.26 & $0.90,1.76$ & 5 & 0.30 & $0.12,0.72$ \\
\hline Cohort & 1 & 0.34 & $0.21,0.55$ & 1 & 2.54 & $2.20,2.93$ & 1 & 1.83 & $1.60,2.11$ & 1 & 0.19 & $0.16,0.22$ \\
\hline Cross-sectional & 8 & 0.17 & $0.14,0.21$ & 8 & 1.41 & $1.22,1.64$ & 8 & 1.39 & $1.12,1.72$ & 8 & 0.47 & $0.38,0.58$ \\
\hline \multicolumn{13}{|l|}{ Quality Assessment Score } \\
\hline High (7-10) & 5 & 0.56 & $0.38,0.81$ & 5 & 1.78 & $1.35,2.33$ & 5 & 1.33 & $0.98,1.80$ & 5 & 0.24 & $0.11,0.55$ \\
\hline Low (0-6) & 9 & 0.18 & $0.15,0.23$ & 9 & 1.39 & $1.21,1.61$ & 9 & 1.40 & $1.14,1.71$ & 9 & 0.47 & $0.39,0.58$ \\
\hline \multicolumn{13}{|l|}{ Study Outcome } \\
\hline Medication overdose & 6 & 0.22 & $0.17,0.27$ & 6 & 1.57 & $1.23,1.99$ & 6 & 1.67 & $1.47,1.90$ & 6 & 0.35 & $0.20,0.61$ \\
\hline Prescription opioid overdose & 6 & 0.34 & $0.14,0.83$ & 6 & 1.64 & $1.40,1.93$ & 6 & 1.25 & $0.85,1.83$ & 6 & 0.42 & $0.26,0.68$ \\
\hline Overdose of any substance & 2 & 0.25 & $0.12,0.51$ & 2 & 1.09 & $1.03,1.16$ & 2 & 1.09 & $0.76,1.56$ & 2 & 0.28 & $0.07,1.11$ \\
\hline \multicolumn{13}{|l|}{ Exclusions } \\
\hline Bohnert et al. 2011 and Paulozzi et al. & 12 & 0.23 & $0.17,0.32$ & 12 & 1.53 & $1.30,1.79$ & 12 & 1.48 & $1.26,1.73$ & 12 & 0.44 & $0.35,0.57$ \\
\hline
\end{tabular}

medication to treat their illness and these medications, (e.g. benzodiazepines, anti-depressants, barbiturates) interact with opioids to increase the risk of fatal and non-fatal overdose (Jones et al. 2012; Maurer and Bartkowski 1993; U.S. Food and Drug Administration 2016). Patients with psychiatric disorder may also self-medicate with alcohol, which combined with opioids, can also increase the risk of fatal or non-fatal overdose (Gudin et al. 2013). Additionally, psychiatric and substance use disorders often co-occur (Mueser et al. 1998; Nunes and Levin 2004). While all studies examined found increased risk for PDO, there was significant heterogeneity in the effect estimates across studies. The heterogeneity in the psychiatric disorder meta-analysis results may stem from

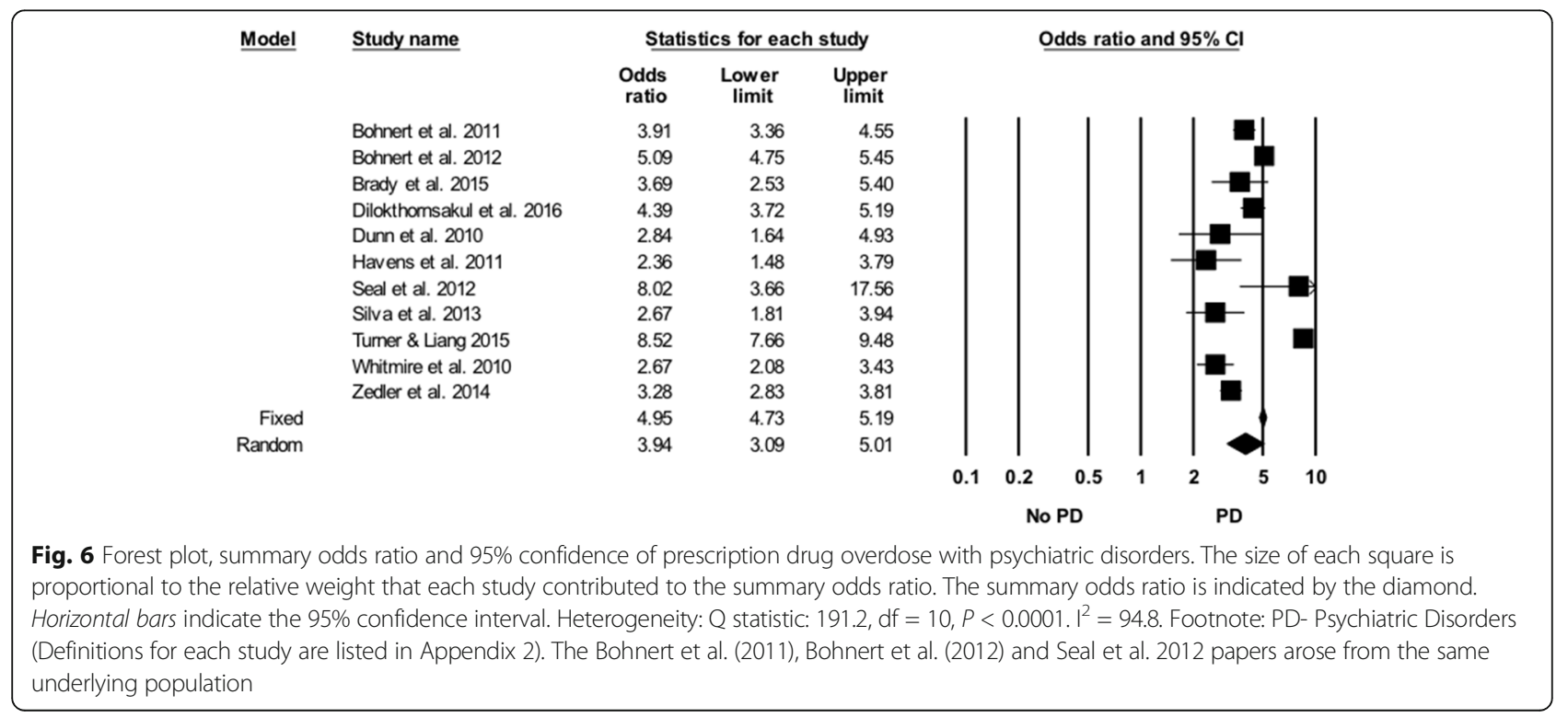




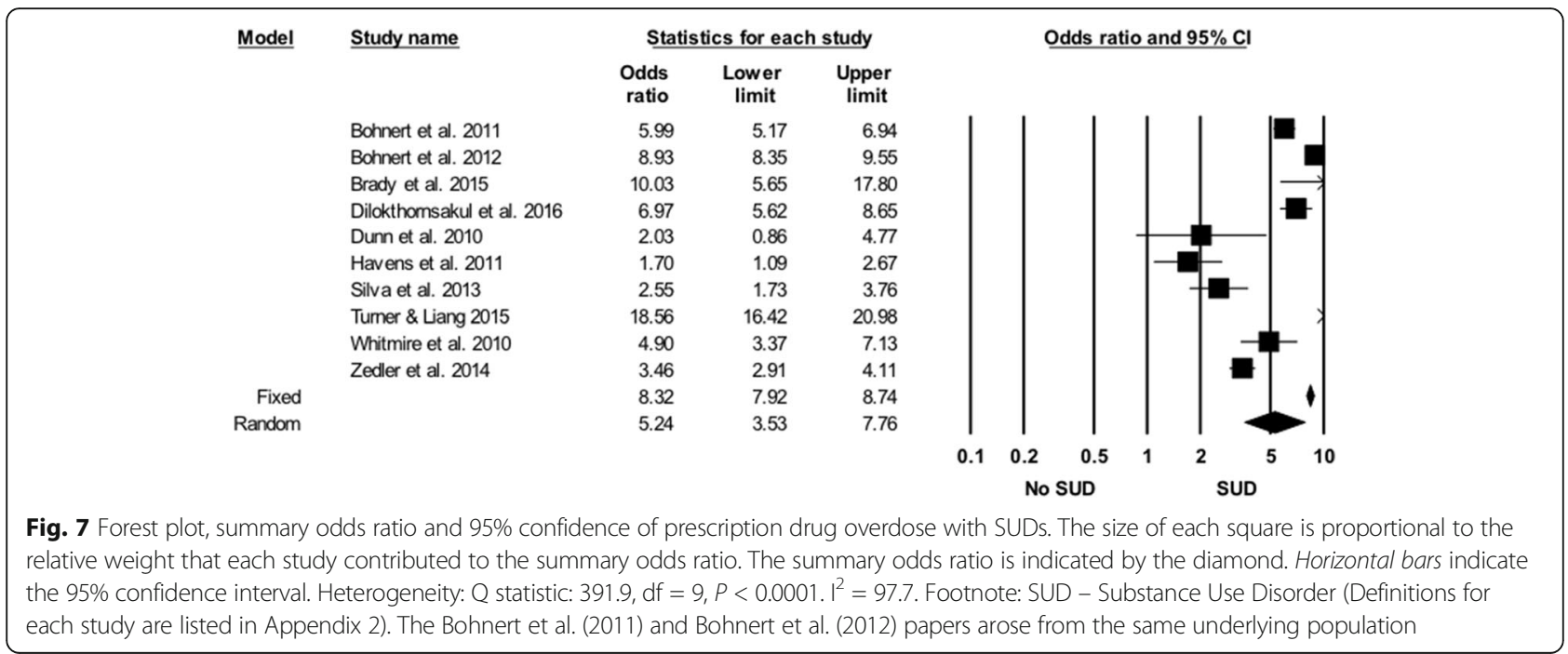

the fact that each of these risk markers is a general categorization that groups multiple psychiatric disorders when in fact, certain psychiatric disorders, such as anxiety disorders or depressive disorders, may have greater risk for PDO than other psychiatric disorders (Seal et al. 2012). Further, the prevalence of specific psychiatric disorders may differ from study to study, leading to varied effect estimates. Similarly, the prevalence of risk for specific psychiatric disorders among these populations e.g. populations that experience more stressors, such as veterans, may be at greater risk for PDO than the general population, may contribute to heterogeneity. Additionally, heterogeneity in the study ORs may result from lack of specificity in the study outcome. One study, Seal et al. (2012), examines the effect of having any psychiatric disorder inclusive of SUDs, which likely results in a greater odds ratio when compared with the other studies which do not include SUDs in their definition of psychiatric disorders. Seal et al. also examines prescription opioidrelated accidents. Many more people suffer from opioidrelated adverse events (e.g. constipation, malaise, fatigue, lethargy, respiratory failure, non-fatal opioid poisoning) and opioid-related accidents than die from prescription opioid-related intoxication (Seal et al. 2012; Hartung et al. 2007). Additionally, Seal et al. restrict their analysis to veterans experiencing serious non-cancer pain and thus, the findings of this study might not be generalizable to veterans experiencing cancer-related pain or nonveterans (Bohnert et al. 2011; Seal et al. 2012). Bohnert et al. (2011) found that risk for opioid overdose death was greater for veterans with cancer-related pain than for veterans with non-cancer related pain. These possible explanations highlight the fact that crude study odds ratios included in the meta-analysis may differ in the degree to which they are affected by confounding and effect measure modification.

The heterogeneity in the SUDs finding likely stems from the different definitions of a SUD in these studies. The two studies with lower odds ratios used atypical definitions of SUDs (Dunn et al. 2010; Havens et al. 2011a). In Dunn et al. (2010), the definition of SUD is "substance abuse". In the 2013, Diagnostic and

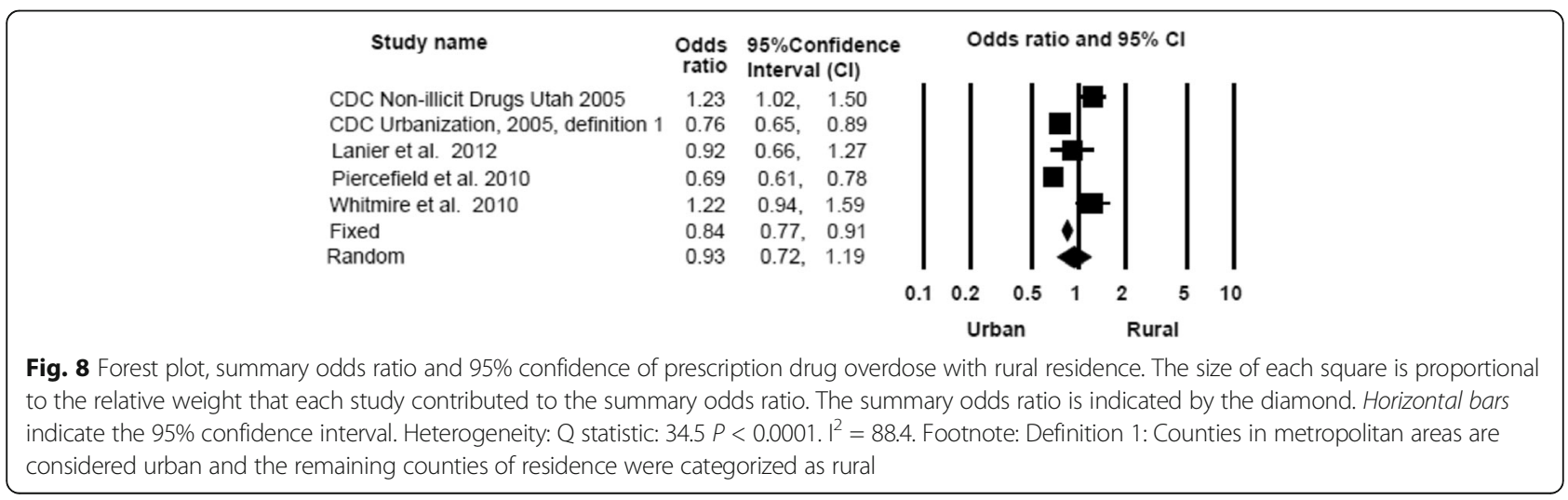


Statistical Manual of Mental Health Disorders, the diagnostic terms "substance abuse" and "substance dependence" were replaced in favor of "SUD." It may be that individuals categorized as having "substance abuse" had less risk of PDO than people who would be categorized as having an "SUD." The Havens et al. (2011a) study is crosssectional and examined non-fatal overdose in rural drug users. It did not examine SUDs per se, but rather "ever going to drug treatment" (Havens et al. 2011a). Given that this study examined a rural area and that there is a lack of basic substance abuse treatment services in rural areas and drug treatment services are underutilized in rural areas, it is likely that drug treatment utilization would not be prevalent. Operationalizing "Ever going to drug treatment" as a diagnosis of an "SUD" may be a poor proxy in a rural setting.

The findings regarding urban/rural as a risk marker are mixed. The largest increases in PDO death rates have occurred in rural areas with rates of PDO deaths in rural areas reaching and sometimes exceeding those in urban areas (Paulozzi and Xi 2008; Park and Bloch 2016). Rossen et al. (2013) found that drug poisoning death rates in rural areas in the United States increased nearly $400 \%$ from 1999 to 2009, while death rates in urban areas in the United States increased almost 280\% from 1999 to 2009. Drug poisoning trends increased more steeply in rural areas because the age-adjusted poisoning death rates were much lower in rural areas at the start of the time period (Rossen et al. 2013). Notably, the highest drug poisoning death rates were found in central metropolitan areas (Rossen et al. 2013). Thus, there is an interaction between urban/rural location and time. An alternative explanation for the heterogeneity in the effect estimates of urban/rural status on PDO may stem from the wide variation in the definitions of "urban" and "rural" used across studies. There is no one accepted definition of "urban" and "rural". Some studies used micropolitan and metropolitan areas to define urban (Centers for Disease Control Prevention 2005; Centers for Disease Control and Prevention 2005); others identified "urban" and "rural" counties according to varying thresholds of population density (Lanier et al. 2012; Piercefield et al. 2010), and one study used county accountability regions (Appendix 2) (Whitmire and Adams 2010). These varying definitions may mean that areas of varying urbanicity and rurality are being grouped together and compared, which would result in an attenuation of the effect of urban/rural on PDO.

Several studies have reported that the epidemics of PDO and nonmedical prescription drug use have not been concentrated in metropolitan areas (Wunsch et al. 2009; Paulozzi and Xi 2008; Centers for Disease Control and Prevention 2005; Havens et al. 2011b; Wang et al. 2013).
This is noteworthy because previous research on drug use and drug overdose epidemics has focused on urban areas (Coffin et al. 2003; Hembree et al. 2005). Research aimed at understanding differences in urban/rural prescription drug use is scant. To help appreciate why there are urban/ rural differences in nonmedical opioid use, Keyes et al. (2014) conceptualized several reasons why individuals residing in rural counties may be vulnerable to nonmedical prescription drug use and abuse. Keyes et al. hypothesized that increased sales of opioids in rural areas led to greater availability for nonmedical use of prescription opioids and that close-knit kinship and social networks allowed for faster dispersion of prescription opioids for those at risk. Further, Keyes et al. (2014) posit that increasing economic hardship and unemployment and out-migration of upwardly mobile young adults create environmental stressors that contribute to risk for drug abuse. Cicero and colleagues (2007) found that in areas where there was more therapeutic use of prescription opioids there was also more prescription opioid abuse. Wang and colleagues examined factors associated with nonmedical prescription opioid use, and found that correlates of nonmedical prescription opioid use were similar for urban and rural areas (Higgins et al. 2003). Other geographical constructs, such as region or state, may interact with the urban/rural context. Regional and local prescribing patterns and availability of other drugs may affect PDO risk.

\section{Strengths and limitations}

This systematic review uses standard meta-analysis guidelines to quantitatively assess risk markers for PDO. The findings may aid clinicians in identifying patients at heightened risk for PDO. This review is also comprehensive because it covers studies conducted over several decades and in different population groups.

Results from this meta-analysis should be interpreted with caution. First, the studies reviewed did not focus exclusively on PDO or PDO death. This review includes studies that examined non-fatal overdose (Coben et al. 2010; Havens et al. 2011a); PDO as defined in this study may be related to combining prescription and illicit drug use (Paulozzi et al. 2012) and may include PDO of intentional and underdetermined intent (Rudd et al. 2016). The inclusion of these studies decreases the specificity of the outcome measurement. However, non-fatal overdose is understudied. Examining non-fatal overdose is important because these incidents are near misses and can help researchers understand more about the rarer occurrence of overdose death. Further, it is not always clear-cut what should be categorized as PDO and if it should be separated from overdose overall. 
Second, this review presents SOR from the random effects model in the presence of unexplained heterogeneity for each of the six risk markers. Some researchers favor not presenting a SOR in the presence of a large amount of unexplained heterogeneity since summary measures generated from random effects models are not always more conservative than summary measures of fixed effect estimates (Higgins et al. 2003; Higgins and Green 2011). Additionally, large unexplained heterogeneity suggests that studies may be evaluating different effects or compounding biases (Higgins et al. 2003; Higgins and Green 2011). While unexplained heterogeneity is not uncommon in meta-analyses of observational studies, it means that less emphasis should be placed on the SOR. Further, this heterogeneity may stem for factors that were not able to be controlled for in this study, such as changing in tolerance to opioids or mixing of different drugs including prescription opioids, heroin or illegal manufactured fentanyl.

Third, this meta-analysis did not include several important risk markers because the number of studies examining these risk markers was too small. Paulozzi et al. (2012), Lanier et al. (2012) and Hartung et al. (2007) reported that type of opioid was strongly associated with PDO death. Type of drug, dose, potency of opioid and duration action, and polysubstance use are all related to risk of PDO (Paulozzi et al. 2012; Peirce et al. 2012; Volkow and Thomas 2016). Additionally, frequent ED utilization and doctor shopping are found to be extremely predictive of subsequent PDO death and their associations with PDO are much stronger than with the risk markers examined in this review (Peirce et al. 2012; Brady et al. 2015). Future systematic reviews may update the present meta-analysis when more epidemiologic evidence has accumulated for emerging risk markers, such as type of drug, dose, potency of opioid, duration of action, polysubstance use, ED utilization and other healthcare utilization.

Finally, the literature included in this review spanned a long period of time. It is likely that risk markers and the strength of their association may change over time. For instance, geospatial risk for PDO may change with drug availability and implementation of laws to prevent diversion. Additionally, during parts of the study period, changes in the availability of drugs and opioids may lead to changes in associated risk markers. Spikes in PDO deaths have been associated with long-acting opioids, such as methadone at certain times and other times, potent legally and illegally produced opioids, such as fentanyl have been related to increases in PDO deaths (Rudd 2016; Dunn et al. 2010; Paulozzi et al. 2012; Lanier et al. 2012).

\section{Conclusions}

This meta-analysis assesses six risk markers for PDO that were commonly examined across studies of drug overdose: sex, age, race, comorbid psychiatric disorders, SUDs and area of residence. It reveals that SUD is the risk marker most strongly associated with PDO, followed by psychiatric disorders, white race, age 35-44 years and male sex. Rural residence does not appear to be significantly associated with PDO. Future research on PDO can address gaps in the literature, such as the underlying reasons for prescription drug use, and understanding the comorbidities and health utilization patterns to help identify individuals at greatest risk for PDO. Findings of this review may aid clinicians in risk assessment while prescribing opioid analgesics and inform policymakers to more effectively allocate resources for intervention programs.

\section{Appendix 1}

Search strategy

Medical Subject Headings (MeSH) for Medline OVID:

1) explode prescription drugs/ and explode drug overdose/;

2) explode prescription drugs/ and explode Poison Control Centers/;

3) (explode prescription drugs/ or explode Prescription Drug Misuse/ and explode Opioid-Related Disorders/ or explode Substance-Related Disorders/ or substance-related disorders/ or amphetamine-related disorders/ or drug overdose/ or neonatal abstinence syndrome/ or opioid-related disorders/ or psychoses, substance-induced/ or substance withdrawal syndrome/ or "phenomena and processes (non-MeSH)"/) and (explode Analgesics/ or explode Prescription Drug Misuse/ and explode Analgesics/ or explode Controlled Substances/).

MeSH for PsycInfo:

1) explode Prescription Drugs/ or explode Analgesic Drugs/ or explode opiates/ and explode Drug Overdoses/or explode Drug Abuse/ or explode Drug Dependency/.

The automated search used the following search strategy for indexed and non-indexed databases: (overdose or substance misuse or drug-related death or addiction disorder) or (non-fatal overdose or prescription drug misuse) or (opioid-related death or (opioids and mortality) or drug poisoning) and (chronic pain or chronic pain patients or opioid therapy or opioid analgesic or prescription pain reliever or controlled substances or prescription drug). 


\section{Appendix 2}

Table 8 Definitions for psychiatric disorder and substance use disorder by study

\begin{tabular}{|c|c|}
\hline & Risk marker definition \\
\hline First author, Year & Psychiatric Disorder (PD) \\
\hline $\begin{array}{l}\text { Bohnert et al. } \\
2011^{\mathrm{a}}\end{array}$ & Non-substance use psychiatric disorders \\
\hline $\begin{array}{l}\text { Bohnert et al. } \\
2012^{\mathrm{a}}\end{array}$ & $\begin{array}{l}\text { Bipolar I or II disorders, Any depressive } \\
\text { disorder, Post-traumatic stress disorder, } \\
\text { other anxiety disorder, and schizophrenia }\end{array}$ \\
\hline Brady et al. 2015 & $\begin{array}{l}\text { Depression diagnosis (ICD-10 codes 298, } \\
311,309.0,309.1)\end{array}$ \\
\hline $\begin{array}{l}\text { CDC Non-illicit } \\
\text { Drugs Utah } 2005\end{array}$ & N/A \\
\hline $\begin{array}{l}\text { CDC Urbanization, } \\
\text { New Mexico, } 2005^{\mathrm{b}}\end{array}$ & N/A \\
\hline $\begin{array}{l}\text { Dilokthornsakul } \\
\text { et al. } 2016\end{array}$ & $\begin{array}{l}\text { "Other psychiatric illness" (includes depression, } \\
\text { bipolar/mixed mania, schizophrenia, anxiety/ } \\
\text { panic/obsessive compulsive, personality disorder, } \\
\text { other psychosis; excludes drug/alcohol abuse) }\end{array}$ \\
\hline Dunn et al. 2010 & Depression diagnosis \\
\hline Havens et al. 2011a & $\begin{array}{l}\text { Major depressive disorder, generalized anxiety } \\
\text { disorder, post-traumatic stress disorder, or } \\
\text { antisocial personality disorder }\end{array}$ \\
\hline
\end{tabular}

Substance Use Dis
Any SUD including
Any SUD including
Drug dependence
(ICD-10 code 304)
N/A

N/A

Drug/alcohol abuse (ICD-9 codes 303.xx, 304.xx)

Substance abuse diagnosis two years prior to entry in the cohort

Ever in drug treatment

N/A

The Utah Department of Health considers an urban county to have a population density exceeded 100 persons per sq. mile. Using this classification, only four counties in the state of Utah are considered "urban": Salt Lake, Davis, Utah, and Weber.

County of residence was considered urban if the county population exceeded 500 persons per sq. mile of land area, with the remainder termed rural counties. Two counties: Oklahoma and Tulsa were categorized as "urban".

N/A

Mental health diagnoses (ICD-CM-9 codes 290-319: N/A

including depressive disorders, anxiety disorders,

alcohol use disorders, drug use disorders) and post-traumatic stress disorder

\section{Silva et al. 2013 \\ Turner and Liang \\ 2015}

Care in a psychiatric hospital

Whitmire and Adams 2010

\section{Depression diagnosis}

"Mental disorders" excluding drug dependence
Ever in drug treatment (excludes alcohol abuse)
"Other substance abuse"

Drug dependence

N/A

N/A

Rural/urban classification variable was created based on the North Carolina accountability regions. The ten counties that were a part of the accountability regions and used to define the "urban" classification are: Buncombe, Cumberland, Davidson, Durham, Forsyth, Gaston, Guilford, Mecklenburg, Onslow, and Wake counties.

Substance abuse and nonopioid N/A substance dependence (excludes opioid dependence) 


\section{Abbreviations}

CDC: Centers for disease control and prevention; Cl: Confidence interval; df: Degrees of freedom; ED: Emergency department; OTC: Over-the-counter; PDO: Prescription drug overdose; SOR: Summary odds ratios; SUD: Substance use disorder

\section{Funding}

This study was supported by the National Center for Injury Prevention and Control of the Centers for Disease Control and Prevention (Grant 1 R49 CE002096). Dr. DiMaggio also was supported by the National Institute of Child Health and Human Development (Grant R01-HD087460). Dr. Keyes was also supported by the National Institutes of Health K01 AA021511.

The contents of the manuscript are solely the responsibility of the authors and do not necessarily reflect the official views of the funding agency.

\section{Authors' contributions}

JEB designed the study. GL, KMK, and CD directed JEB and RG work on the meta-analysis. JEB conducted the analysis and wrote the first full draft of the manuscript. RG updated the analysis. All authors contributed to the conceptualization of the paper, critically reviewed all drafts and contributed to the revision of the article. All authors read and approved the final manuscript.

\section{Ethics approval and consent to participate}

The manuscript is a review of published articles and report. It is considered non-human subjects research by Columbia University's institutional review board.

\section{Competing interests}

Joanne Brady is currently employed by GlaxoSmithKline. This article is unrelated to her work at GlaxoSmithKline and was written prior to her employment there. Dr. Guohua Li and Dr. Charles DiMaggio are editors of Injury Epidemiology, and Dr. Katherine Keyes serves on the editorial board of Injury Epidemiology. They were not involved in the review or handling of this manuscript.

\section{Publisher's note}

Springer Nature remains neutral with regard to jurisdictional claims in published maps and institutional affiliations.

\section{Author details}

'Department of Epidemiology, Columbia University Mailman School of Public Health, New York, NY, USA. ${ }^{2}$ Center for Injury Epidemiology and Prevention, Columbia University, New York, NY, USA. ${ }^{3}$ Department of Surgery, Division of Trauma, New York University, New York, NY, USA. ${ }^{4}$ Department of Anesthesiology, Columbia University College of Physicians and Surgeons, New York, NY, USA.

\section{Received: 11 March 2017 Accepted: 20 June 2017}

\section{Published online: 07 August 2017}

\section{References}

Bateman DN, Bain M, Gorman D, Murphy D. Changes in paracetamol, antidepressants and opioid poisoning in Scotland during the 1990s. QJM 2003;96(2):125-132. PMID: 12589010. English.

Bauer LK, Brody JK, León C, Baggett TP. Characteristics of homeless adults who died of drug overdose: a retrospective record review. J Health Care Poor Underserved. 2016;27(2):846-59.

Bohnert AS, Valenstein M, Bair MJ, Ganoczy D, McCarthy JF, Ilgen MA, et al. Association between opioid prescribing patterns and opioid overdoserelated deaths. JAMA 2011;305(13):1315-1321. PMID: 21467284. English.

Bohnert AS, Ilgen MA, Ignacio RV, McCarthy JF, Valenstein M, Blow FC. Risk of death from accidental overdose associated with psychiatric and substance use disorders. [Erratum appears in am J Psychiatry. 2012 Jan;169(1):99]. Am J Psychiatry 2012;169(1):64-70. PMID: 21955932. English.

Brady JE, DiMaggio CJ, Keyes KM, Doyle JJ, Richardson LD, Li G. Emergency department utilization and subsequent prescription drug overdose death. Ann Epidemiol. 2015;25(8):613-9.

Buckley NA, McManus PR. Changes in fatalities due to overdose of Anxiolytic and sedative drugs in the UK (1983-1999). Drug Saf. 2004;27(2):135-41.

Burt BA. Definitions of risk. J Dent Educ 2001;65(10):1007-1008. PMID: 11699970. Epub 2001/11/09. English.
Cai R, Crane E, Poneleit K, Paulozzi L. Emergency department visits involving nonmedical use of selected prescription drugs in the United States, 2004-2008. J Pain Pall Care Pharmacother 2010;24(3):293-297. PMID: 20718652. English.

Calcaterra S, Glanz J, Binswanger IA. National trends in pharmaceutical opioid related overdose deaths compared to other substance related overdose deaths: 1999-2009. Drug Alcohol Depend 2013;131(3):263-270. PMID: 23294765. Epub 2013/01/09. eng.

Caudarella A, Dong H, Milloy MJ, Kerr T, Wood E, Hayashi K. Non-fatal overdose as a risk factor for subsequent fatal overdose among people who inject drugs. Drug Alcohol Depend. 2016;162:51-5.

Centers for Disease Control and Prevention. Unintentional deaths from drug poisoning by urbanization of area-New Mexico, 1994-2003. MMWR Morb Mortal Wkly Rep. 2005;54(35):870-873. PMID: 16151371.

Centers for Disease Control and Prevention. Vital signs: overdoses of prescription opioid pain relievers-United States, 1999-2008. MMWR Morb Mortal Wkly Rep. 2011;60(43):1487-1492. PMID: 22048730. English.

Centers for Disease Control and Prevention. CDC grand rounds: prescription drug overdoses - a U.S. epidemic. MMWR Morb Mortal Wkly Rep. 2012;61(1):10-13. PMID: 22237030. English.

Centers for Disease Control and Prevention. Poisoning 2015. Available from: https://www.cdc.gov/homeandrecreationalsafety/poisoning/index.html. Accessed 1 March 2017.

Centers for Disease Control Prevention. Increase in poisoning deaths caused by non-illicit drugs-Utah, 1991-2003. MMWR Morb Mortal Wkly Rep. 2005;54(2):33-36. PMID: 15660016. English.

Centers for Disease Control Prevention. Overdose deaths involving prescription opioids among Medicaid enrollees - Washington, 2004-2007. MMWR Morb Mortal Wkly Rep. 2009;58(42):1171-1175. PMID: 19875978. English.

Centers for Disease Control Prevention. Drug overdose deaths-Florida, 2003-2009. MMWR Morb Mortal Wkly Rep. 2011;60(26):869-872. PMID: 21734633. English.

Centers for Disease Control Prevention. Vital signs: risk for overdose from methadone used for pain relief - United States, 1999-2010. MMWR Morb Mortal Wkly Rep. 2012 Jul 6;61(26):493-497. PMID: 22763888. English.

Cerdá M, Ransome Y, Keyes KM, Koenen KC, Vlahov D, Galea S. Revisiting the role of the urban environment in substance use. The case of analgesic overdose fatalities. AJPH. 2013;103(12):2252-60.

Cheng M, Sauer B, Johnson E, Porucznik C, Hegmann K. Comparison of opioidrelated deaths by work-related injury. Am J Ind Med. 2013;56(3):308-16.

Cicero TJ, Surratt H, Inciardi JA, Munoz A. Relationship between therapeutic use and abuse of opioid analgesics in rural, suburban, and urban locations in the United States. Pharmacoepidemiol Drug Saf 2007;16(8):827-840. PMID: 17636553. Epub 2007/07/20. eng.

Coben JH, Davis SM, Furbee PM, Sikora RD, Tillotson RD, Bossarte RM. Hospitalizations for poisoning by prescription Opioids, sedatives, and tranquilizers. Am J Prev Med. 2010;38(5):517-24.

Cochella S, Bateman K. Provider detailing: an intervention to decrease prescription opioid deaths in Utah. Pain Med 2011;12 Suppl 2:S73-S76. PMID: 21668760. English.

Coffin PO, Galea S, Ahern J, Leon AC, Vlahov D, Tardiff K. Opiates, cocaine and alcohol combinations in accidental drug overdose deaths in new York City, 1990-98. Addiction 2003;98(6):739-747. PMID: 12780362. English.

Compton WM, Volkow ND. Abuse of prescription drugs and the risk of addiction. Drug Alcohol Depend 2006a;83 Suppl 1:S4-S7. PMID: 16563663. Epub 2006/03/28. eng.

Compton WM, Volkow ND. Major increases in opioid analgesic abuse in the United States: concerns and strategies. Drug Alcohol Depend 2006b;81(2):103-107. PMID: 16023304. Epub 2005/07/19. eng.

Crombie IK, McLoone P. Does the availability of prescribed drugs affect rates of self poisoning? Br J Gen Pract. 1998;48(433):1505-6.

Degenhardt L, Hall W, Adelstein BA. Ambulance calls to suspected overdoses: new South Wales patterns July 1997 to June 1999. Aust N Z J Public Health 2001;25(5):447-450. PMID: 11688626. English.

Dhalla IA, Mamdani MM, Sivilotti ML, Kopp A, Qureshi O, Juurlink DN. Prescribing of opioid analgesics and related mortality before and after the introduction of long-acting oxycodone. CMAJ. 2009;181(12):891-896. PMID: 19969578. PMCID: PMC2789126. English.

Diez Roux AV. The study of group-level factors in epidemiology: rethinking variables, study designs, and analytical approaches. Epidemiol Rev 2004;26:104-111. PMID: 15234951. Epub 2004/07/06. eng. 
Dilokthornsakul P, Moore G, Campbell JD, Lodge R, Traugott C, Zerzan J, et al. Risk factors of prescription opioid overdose among Colorado Medicaid beneficiaries. J Pain. 2016;17(4):436-443.PMID: 2016-08204-001. English.

Dowell D, Haegerich TM, Chou R. CDC guideline for prescribing Opioids for chronic pain-United States, 2016. JAMA 2016;315(15):1624-1645. PMID: 26977696. Epub 2016/03/16. Eng.

Dunn KM, Saunders KW, Rutter CM, Banta-Green CJ, Merrill JO, Sullivan MD, et al. Opioid prescriptions for chronic pain and overdose: a cohort study. Ann Intern Med. 2010;152(2):85-92.

Fernandez W, Hackman H, McKeown L, Anderson T, Hume B. Trends in opioidrelated fatal overdoses in Massachusetts, 1990-2003. J Subst Abus Treat 2006;31(2):151-156. PMID: 16919742. English.

Fischer B, Popova S, Rehm J, Ivsins A. Drug-related overdose deaths in British Columbia and Ontario, 1992-2004. Can J Public Health 2006:97(5):384-387. PMID: 17120877. English.

Gilchrist J, Ballesteros MF, Parker EM. Vital signs: unintentional injury deaths among persons aged 0-19 years - United States, 2000-2009. Morb Mortal Wkly Rep. 2012;61(15):270-6.

Gomes T, Mamdani MM, Dhalla IA, Paterson JM, Juurlink DN. Opioid dose and drug-related mortality in patients with nonmalignant pain. Arch Intern Med 2011;171(7):686-691. PubMed PMID: 21482846. English.

Green CR, Ndao-Brumblay SK, West B, Washington T. Differences in prescription opioid analgesic availability: comparing minority and white pharmacies across Michigan. J Pain. 2005;6(10):689-99.

Green TC, Grau LE, Carver HW, Kinzly M, Heimer R. Epidemiologic trends and geographic patterns of fatal opioid intoxications in Connecticut, USA: 1997-2007. Drug Alcohol Depend. 2011;115(3):221-228. PMID: 21131140. PMCID: PMC3095753. English.

Gudin JA, Mogali S, Jones JD, Comer SD. Risks, management, and monitoring of combination opioid, benzodiazepines, and/or alcohol use. Postgrad Med. 2013;125(4):115-30.

Hall WD, Degenhardt LJ, Lynskey MT. Opioid overdose mortality in Australia, 1964-1997: birth-cohort trends. Med J Aust 1999;171(1):34-37. PMID: 10451670. English.

Hall AJ, Logan JE, Toblin RL, Kaplan JA, Kraner JC, Bixler D, et al. Patterns of abuse among unintentional pharmaceutical overdose fatalities. JAMA. 2008;300(22):2613-2620. PMID: 19066381. English.

Harlow KC. Patterns of prescription drug mortality in Texas: 1976-1986. J Drug Issues. 1991;21(3):543-555. PMID: 1992-05793-001. English.

Hartung DM, Middleton L, Haxby DG, Koder M, Ketchum KL, Chou R. Rates of adverse events of long-acting opioids in a state Medicaid program.[Erratum appears in Ann Pharmacother. 2007 sep;41(9):1552]. Ann Pharmacother 2007;41(6):921-928. PMID: 17504834. English.

Hasin DS, Stinson FS, Ogburn E, Grant BF. Prevalence, correlates, disability, and comorbidity of DSM-IV alcohol abuse and dependence in the United States: results from the National Epidemiologic Survey on alcohol and related conditions. Arch Gen Psychiatry 2007;64(7):830-842. PMID: 17606817. Epub 2007/07/04. eng.

Havens JR, Oser CB, Knudsen HK, Lofwall M, Stoops WW, Walsh SL, et al. Individual and network factors associated with non-fatal overdose among rural Appalachian drug users. Drug Alcohol Depend 2011a;115(1-2):107-112. PMID: 21126831. English.

Havens JR, Young AM, Havens CE. Nonmedical prescription drug use in a nationally representative sample of adolescents: evidence of greater use among rural adolescents. Arch Pediatr Adolesc Med 2011b;165(3):250-255. PMID: 21041587. Epub 2010/11/03. eng.

Heckathorn DD. Respondent-driven sampling: a new approach to the study of hidden populations. Soc Probl. 1997;44:174-99.

Hembree C, Galea S, Ahern J, Tracy M, Markham Piper T, Miller J, et al. The urban built environment and overdose mortality in new York City neighborhoods. Health Place 2005;11(2):147-156. PMID: 15629682. English.

Herzog R, Alvarez-Pasquin MJ, Diaz C, Del Barrio JL, Estrada JM, Gil A. Are healthcare workers' intentions to vaccinate related to their knowledge, beliefs and attitudes? A systematic review. BMC Public Health. 2013;13:154. PMID: 23421987. PMCID: PMC3602084. Epub 2013/02/21. eng.

Higgins JP, Green S, editors. Cochrane Handbook for Systematic Reviews of Interventions Version 5.1.0 [updated March 2011]: The Cochrane Collaboration; 2011 [Accessed: August 9, 2013]. Available from http:// handbook.cochrane.org.

Higgins JP, Thompson SG. Quantifying heterogeneity in a meta-analysis. Stat Med 2002;21(11):1539-1558. PMID: 12111919. Epub 2002/07/12. eng.
Higgins JP, Thompson SG, Deeks JJ, Altman DG. Measuring inconsistency in meta-analyses. Br J Med, 2003 Sep 6;327(7414):557-560. PMID: 12958120 PMCID: PMC192859. Epub 2003/09/06. eng.

Hoffman KM, Trawalter S, Axt JR, Oliver MN. Racial bias in pain assessment and treatment recommendations, and false beliefs about biological differences between blacks and whites. Proc Natl Acad Sci U S A. 2016;113(16):4296-301.

Hulse GK, Robertson SI, Tait RJ. Adolescent emergency department presentations with alcohol- or other drug-related problems in Perth. West Aust Addict. 2001;96(7):1059-67.

Insurance Institute for Highway Safety. Fatality Facts: Gender, 2015: Highway Loss Data Institute 2017. Available from: http://www.iihs.org/iihs/topics/t/generalstatistics/fatalityfacts/gender . Accessed 1 Mar 2017.

Johnson EM, Lanier WA, Merrill RM, Crook J, Porucznik CA, Rolfs RT, et al. Unintentional Prescription Opioid-Related Overdose Deaths. Utah: Description of Decedents by Next of Kin or Best Contact 2008-2009. J Gen Intern Med. 2012;28(4):1-8.

Jones JD, Mogali S, Comer SD. Polydrug abuse: a review of opioid and benzodiazepine combination use. Drug Alcohol Depend. 2012;125(1):8-18.

Keyes KM, Cerdá M, Brady JE, Havens J, Galea S. Understanding the rural-urban differences in nonmedical prescription opioid use and abuse in the United States. Am J Public Health. 2014;104(2):e52-9.

Lanier WA, Johnson EM, Rolfs RT, Friedrichs MD, Grey TC. Risk factors for prescription Opioid-related death, Utah, 2008-2009. Pain Med. 2012;13(12):1580-9.

Lloyd BK, McElwee PR. Trends over time in characteristics of pharmaceutical drug-related ambulance attendances in Melbourne. Drug Alcohol Rev. 2011 May;30(3):271-280 PMID: 21545557. English.

Lynskey M, Hall W. Jurisdictional trends in opioid overdose deaths, 1988-96. Aust N Z J Public Health 1998;22(7):802-807. PMID: 9889447. English.

Mack KA. Vital signs: overdoses of prescription opioid pain relievers and other drugs among women - United States, 1999-2010. MMWR Morb Mortal Wkly Rep 2013;62(26):537-542. PMID: 23820967. Epub 2013/07/04. eng.

Maurer PM, Bartkowski RR. Drug interactions of clinical significance with opioid analgesics. Drug Saf. 1993;8(1):30-48.

McKenzie MS, McFarland BH. Trends in antidepressant overdoses. Pharmacoepidemiol Drug Saf 2007;16(5):513-523. PMID: 17200994. Epub 2007/01/04. eng.

Miech R, Koester S, Dorsey-Holliman B. Increasing US mortality due to accidental poisoning: the role of the baby boom cohort. Addiction 2011;106(4):806-815. PMID: 21205051. English.

Moher D, Liberati A, Tetzlaff J, Altman DG. Preferred reporting items for systematic reviews and meta-analyses: the PRISMA statement. PLoS Med. 2009;6(7):e1000097. PMID: 19621072. PMCID: PMC2707599. Epub 2009/07/22. eng.

Morrison RS, Wallenstein S, Natale DK, Senzel RS, Huang L-L. "we don't carry that" - failure of pharmacies in predominantly nonwhite neighborhoods to stock opioid analgesics. N Engl J Med. 2000;342(14):1023-6.

Mueller MR, Shah NG, Landen MG. Unintentional prescription drug overdose deaths in New Mexico, 1994-2003. Am J Prev Med 2006;30(5):423-429. PMID: 16627130. English.

Mueser KT, Drake RE, Wallach MA. Dual diagnosis: a review of etiological theories. Addict Behav. 1998;23(6):717-34.

Nunes EV, Levin FR. Treatment of depression in patients with alcohol or other drug dependence: a meta-analysis. JAMA. 2004;291(15):1887-96.

Okie S. A flood of opioids, a rising tide of deaths. Erratum appears in N Engl J med. 2011 Jan 20;364(3):290]. N Engl J Med 2010;363(21):1981-1985. PMID: 21083382. English.

Park H, Bloch M. How the epidemic of drug overdose deaths ripples across America the New York times [internet]. 2016. Available from: https://www. nytimes.com/interactive/2016/01/07/us/drug-overdose-deaths-in-the-us. html? $r=1$.

Patrick SW, Schumacher RE, Benneyworth BD, Krans EE, McAllister JM, Davis MM. Neonatal abstinence syndrome and associated health care expenditures: United States, 2000-2009. JAMA. 2012;307(18):1934-1940. PMID: 22546608. Epub 2012/05/02. English

Paulozzi LJ, Stier DD. Prescription drug laws, drug overdoses, and drug sales in New York and Pennsylvania. J Public Health Policy 2010;31(4):422-432. PMID: 21119649. English.

Paulozzi $L, X i$ Y. Recent changes in drug poisoning mortality in the United States by urban-rural status and by drug type. Pharmacoepidemiol Drug Saf 2008;17(10):997-1005. PMID: 18512264. English.

Paulozi $\sqcup$, Budnitz DS, Xi Y. Increasing deaths from opioid analgesics in the United States. Pharmacoepidemiol Drug Saf 2006;15(9):618-627. PMID: 16862602. English. 
Paulozzi LJ, Jones CM, Mack KA, Rudd RA. Vital signs: overdoses of prescription opioid pain relievers - United States, 1999-2008. MMWR Morb Mortal Wkly Rep. 2011;60(43):1487-1492. PMID: 2011-29737-004. English.

Paulozzi LJ, Kilbourne EM, Shah NG, Nolte KB, Desai HA, Landen MG, et al. A history of being prescribed controlled substances and risk of drug overdose death. Pain Med 2012;13(1):87-95. PMID: 22026451. English.

Peirce GL, Smith MJ, Abate MA, Halverson J. Doctor and pharmacy shopping for controlled substances. Med Care 2012;50(6):494-500. PMID: 22410408. English.

Persaud R. Misleading meta-analysis. "fail safe N" is a useful mathematical measure of the stability of results. BMJ. 1996;312(7023):125. PMID: 8555918. PMCID: PMC2349768. Epub 1996/01/13. eng.

Piercefield E, Archer P, Kemp P, Mallonee S. Increase in unintentional medication overdose deaths: Oklahoma, 1994-2006. Am J Prev Med 2010;39(4):357-363. PMID: 20837287. English.

Riley RD, Higgins JP, Deeks JJ. Interpretation of random effects meta-analyses. BMJ. 2011;342:d549. PMID: 21310794. Epub 2011/02/12. eng.

Romelsjo A, Engdahl B, Stenbacka M, Fugelstad A, Davstad I, Leifman A, et al. Were the changes to Sweden's maintenance treatment policy 2000-06 related to changes in opiate-related mortality and morbidity? Addiction 2010;105(9):1625-1632. PMID: 20626377. English.

Rosca P, Haklai Z, Goldberger N, Zohar P, Margolis A, Ponizovsky AM. Mortality and causes of death among users of methadone maintenance treatment in Israel, 1999-2008. Drug Alcohol Depend 2012;125(1-2):160-163. PMID: 22483811. English.

Rossen LM, Khan D, Warner M. Trends and geographic patterns in drug Poisoining deaths in the US 1999-2009. Am J Prev Med. 2013;45(6):e19-25.

Roxburgh A, Bruno R, Larance B, Burns L. Prescription of opioid analgesics and related harms in Australia. Med J Aust. 2011;195(5):280-284. PMID: 21895598. English.

Rudd RA. Increases in drug and Opioid-involved overdose deaths-United States, 2010-2015. MMWR Morb Mortal Wkly Rep. 2016;65(50-51):1445-52.

Rudd RA, Aleshire N, Zibbell JE, Gladden RM. Increases in drug and Opioid overdose deaths-United States, 2000-2014. MMWR Morb Mortal Wkly Rep 2016;64(50-51):1378-1382. PubMed PMID: 26720857. English.

Seal KH, Shi Y, Cohen G, Cohen BE, Maguen S, Krebs EE, et al. Association of mental health disorders with prescription opioids and high-risk opioid use in US veterans of Iraq and Afghanistan. [Erratum appears in JAMA. 2012;307(23):2489]. JAMA 2012;307(9):940-947. PMID: 22396516. English

Shah N, Lathrop SL, Landen MG. Unintentional methadone-related overdose death in New Mexico (USA) and implications for surveillance, 1998-2002. Addiction 2005;100(2):176-188. PMID: 15679747. English.

Shah NG, Lathrop SL, Flores JE, Landen MG. The influence of living along the U.S.-Mexico border on unintentional drug overdose death, New Mexico (USA), 2005-2009. Drug Alcohol Depend 2012;125(1-2):19-26. PMID: 22513379. English.

Silva K, Schrager SM, Kecojevic A, Lankenau SE. Factors associated with history of non-fatal overdose among young nonmedical users of prescription drugs. Drug Alcohol Depend. 2013;128(1-2):104-10.

Singhal A, Tien Y-Y, Hsia RY. Racial-ethnic disparities in Opioid prescriptions at emergency department visits for conditions commonly associated with prescription drug abuse. PLoS One. 2016;11(8):e0159224.

Smith HS. Opioid Metabolism. Mayo Clin Proc. 2009 Jul;84(7):613-624. PMID: 19567715. PMCID: Pmc2704133. English.

Sorenson SB. Gender disparities in injury mortality: consistent, persistent, and larger than you'd think. Am J Public Health. 2011;101(S1):S353-S8.

Stroup DF, Berlin JA, Morton SC, et al. Meta-analysis of observational studies in epidemiology: a proposal for reporting. JAMA. 2000;283(15):2008-12.

Turner BJ, Liang Y. Drug overdose in a retrospective cohort with non-cancer pain treated with Opioids, antidepressants, and/or sedative-hypnotics: interactions with mental health disorders. J Gen Intern Med. 2015;30(8):1081-96.

U.S. Food \& Drug Administration. FDA requires strong warnings for opioid analgesics, prescription opioid cough products, and benzodiazepine labeling related to serious risks and death from combined use. 2016.

Unick GJ, Rosenblum D, Mars S, Ciccarone D. Intertwined epidemics: national demographic trends in hospitalizations for heroin- and opioid-related overdoses, 1993-2009. PLoS One 2013;8(2):e54496. PubMed PMID: 23405084. Pubmed Central PMCID: Pmc3566161. English.

Volkow ND, Thomas MLA. Opioid abuse in chronic pain-misconceptions and mitigation strategies. N Engl J Med. 2016;374(13):1253-63.

Waldron I, McCloskey C, Earle I. Trends in gender differences in accidents mortality: Relationships to changing gender roles and other societal trends. Demographic Research. 2005;13:415-54.
Wang KH, Becker WC, Fiellin DA. Prevalence and correlates for nonmedical use of prescription opioids among urban and rural residents. Drug Alcohol Depend. 2013;127(1-3):156-62.

Warner M, Chen LH, Makuc DM. Increase in fatal poisonings involving opioid analgesics in the United States, 1999-2006. NCHS Data Brief 2009 (22):1-8. PMID: 19796521. English.

Warner M, Chen LH, Makuc DM, Anderson RN, Miniño AM. Drug poisoning deaths in the United States, 1980-2008. NCHS Data Brief. 2011;81:1-8.

Wells GA, Shea B, O'Connell D, et al. The Newcastle-Ottawa scale (NOS) for assessing the quality of nonrandomised studies in meta-analyses [webpage on the internet]. Ottawa Hospital Research Institute: Ottawa,ON; 2011. [Accessed 5 Nov 2016]. Available from: http://www.ohri.ca/programs/clinical_ epidemiology/oxford.asp

Whiteside LK, Walton MA, Bohnert AS, Blow FC, Bonar EE, Ehrlich P, et al. Nonmedical prescription opioid and sedative use among adolescents in the emergency department. Pediatrics. 2013 Nov;132(5):825-832. PMID: 24167166. PMCID: Pmc3813392. Epub 2013/10/30. English.

Whitmire T, Adams G. Unintentional overdose deaths in the North Carolina Medicaid population: prevalence, prescription drug use, and medical care services. State Cen Health Stat Stud. 2010;162

Williamson PA, Foreman KJ, White JM, Anderson G. Methadone-related overdose deaths in South Australia, 1984-1994. How safe is methadone prescribing? Med J Aust 1997;166(6):302-305. PMID: 9087187. English.

Woerle S, Roeber J, Landen MG. Prevalence of alcohol dependence among excessive drinkers in New Mexico. Alcohol Clin Exp Res 2007;31(2):293-298. PMID: 17250622. Epub 2007/01/26. eng.

Wong A, Taylor DM, Ashby K, Robinson J. Changing epidemiology of intentional antidepressant drug overdose in Victoria, Australia Aust N Z J Psychiatry 2010;44(8):759-764. PMID: 20636198. English.

Wunsch MJ, Nakamoto K, Nuzzo PA, Behonick G, Massello W, Walsh SL. Prescription drug fatalities among women in rural Virginia: a study of medical examiner cases. J Opioid Manag 2009;5(4):228-236. PMID: 19736903. English.

Xiang Y, Zhao W, Xiang H, Smith GA. ED visits for drug-related poisoning in the United States, 2007. Am J Emerg Med 2012;30(2):293-301. PMID: 21367556. Epub 2011/03/04. eng.

Zedler B, Xie L, Wang L, Joyce A, Vick C, Kariburyo F, et al. Risk factors for serious prescription opioid-related toxicity or overdose among veterans health administration patients. Pain Med. 2014;15(11):1911-29.

\section{Submit your manuscript to a SpringerOpen ${ }^{\mathcal{O}}$ journal and benefit from:}

- Convenient online submission

- Rigorous peer review

- Open access: articles freely available online

- High visibility within the field

- Retaining the copyright to your article

Submit your next manuscript at $>$ springeropen.com 